\title{
Alterations along the Hypothalamic-Pituitary-Thyroid Axis of the Zebrafish (Danio rerio) after Exposure to Propylthiouracil
}

\author{
Florian Schmidt and Thomas Braunbeck \\ Aquatic Ecology and Toxicology Group, Centre for Organismal Studies, University of Heidelberg, Im Neuenheimer Feld 230, \\ 69120 Heidelberg, Germany
}

Correspondence should be addressed to Florian Schmidt, florian.schmidt@zoo.uni-heidelberg.de

Received 12 January 2011; Revised 17 April 2011; Accepted 11 May 2011

Academic Editor: Jack R. Wall

Copyright (๑) 2011 F. Schmidt and T. Braunbeck. This is an open access article distributed under the Creative Commons Attribution License, which permits unrestricted use, distribution, and reproduction in any medium, provided the original work is properly cited.

\begin{abstract}
In the past, various approaches have been developed to detect adverse effects of pollutants on the thyroid of vertebrates, most of these with special emphasis on the South African clawed frog, Xenopus laevis. Although fish are primarily affected by thyroiddisrupting chemicals, studies into alterations of the thyroid of fish are scarce. Therefore, effects of the reference compound propylthiouracil on histopathology of the thyroid axis were analyzed in a modified early life-stage test with zebrafish (Danio rerio) exposed to propylthiouracil. The test substance induced dose-dependent alterations of thyroidal tissue concomitant with increases in the number of surrounding blood vessels. Despite this massive proliferation of the thyroid, zebrafish were not able to maintain thyroxin concentrations. The pituitary was affected displaying significant alterations in thyroid-stimulating hormone cell counts. Quantitative evaluation of pituitary surface areas revealed a dose-dependent increase of adenohypophyseal tissue. Distinct histopathological effects may contribute to a more easy identification and interpretation of alterations induced by thyroiddisrupting chemicals.
\end{abstract}

\section{Introduction}

Over the past 20 years, the potency of endocrine-disrupting chemicals (EDCs) has attracted attention in numerous toxicological and ecotoxicological studies [1-9]. So far, the main focus of EDCs was clearly on effects on reproductive biology [10-12], but the awareness of potential risks by thyroid system-disrupting chemicals is increasing [13-18]. Therefore, several approaches to detect adverse effects of pollutants on the thyroid system of vertebrates have been developed with special emphasis on the South African clawed frog, Xenopus laevis [19-22], and an OECD guideline has recently been established to detect thyroid system-disrupting chemicals with amphibians as test model [23]. On the other hand, although fish form the most versatile and heterogeneous vertebrate group with regard to anatomy, physiology, reproduction, behavior, and ecology [24-26]approx. $48 \%$ of all vertebrates are fish, which occupy a great variety of ecological niches [26] —studies on alterations of the thyroid system under the influence of pseudothyroidacting substances are still scarce. However, in recent years, there is increasing evidence of effects both in the field $[13,27-32]$ and in the laboratory $[17,33-41]$. So far, only a small selection of these chemicals has been tested under laboratory conditions, mostly with a focus on polychlorinated biphenyls, polyhalogenated aromatic hydrocarbons [42-44], and, more recently, brominated flame retardants $[45,46]$. Perchlorates as a group of water-soluble goitrogens have attracted some interest because of their potency to contaminate drinking water [47].

In many aspects, the thyroid system of fish is similar to the mammalian or the amphibian thyroid system, but there are some differences that have to be taken into account when studying effects of thyroid EDCs in fish. The regulation of thyroidal homeostasis is principally maintained by feedback mechanisms, in which both thyroxin (T4) and triiodothyronine (T3) have negative feedback effects on the release of thyroid-stimulating hormone $(\mathrm{TSH})$ in the 
pituitary, which is the central control organ of the thyroid system [48]. Nevertheless, in contrast to mammals, in fish the central control of thyroid hormone is limited to the production and secretion of T4, which is transformed into the biologically active T3 in peripheral tissues, mainly the liver $[49,50]$. Morphologically, the thyroid of fish also differs from the thyroid of higher vertebrates: instead of a compact organ encapsulated by connective tissue, most fish thyroid follicles are loosely scattered in the gill region along the ventral aorta [51-53]. It has been shown that the thyroid is of endodermal origin. Under the influence of pax2.1 and pax8, its primordium evaginates from the pharyngeal epithelium and adopts a position near the cardiac outflow tract [5456]. The final localization then depends on the development of the ventral aorta demonstrating the connection between thyroidal tissue and adjacent arteries [54]. In mammals, the thyroid primordia fuse with the ultimobranchial body, which differentiates into C-cells during further development [57]. In lower vertebrates such as fish and amphibians, and also in birds, thyroid follicle cells do not merge with the ultimobranchial bodies, which are instead located elsewhere in the body [57-59]. In zebrafish, the first follicle differentiates around 55 hours postfertilization (hpf), and T4-production can be revealed at around $72 \mathrm{hpf}[35,60]$. This thyroid follicle formed first corresponds to the most anterior follicle in the adult fish, and new follicles are added more caudally [60]. This aspect is important for evaluating histopathological changes in the zebrafish thyroid, since follicle maturity and, thus, size represents major endpoints.

Although the thyroid gland acts as the downstreamlocated hormone-producing gland, the key organ for regulation of, for example, growth, development, reproduction, or adaption to environmental challenges along hormonal axes is the pituitary [61]. Regulatory pathways of the thyroid system start with the reception of external and internal sensory information reaching the brain and the hypothalamus. In contrast to higher vertebrates, the role of the thyrotropinreleasing hormone in the regulation of TSH release in fish is less well established [25]. Unlike mammals, teleost fish lack a portal system between the hypothalamus and the pituitary. Instead, there is a direct neuronal connection to endocrine cells through the hypophyseal stalk [62]. The hypothalamus thus directly innervates the pituitary exerting control through secretion of several hormones - in this case, via TSH [63]. The functional significance of TSH is limited to the regulation of $\mathrm{T} 4$ release and iodide uptake by the thyroid follicles [49].

Morphologically, the pituitary in teleost fish is divided into two major parts: (1) the neurohypophysis (pars nervosa; $\mathrm{PN}$ ), which folds down from the diencephalon and (2) the adenohypophysis, which pouches up from the roof of the oral cavity [64]. During development, the neurohypophysisinterdigitates with the adenohypophysis, which on its part can be subdivided into (1) the pars distalis (PD), which can further be divided into the rostral pars distalis (RPD) and the proximal pars distalis (PPD) and (2) the pars intermedia (PI; for further details, see Figure 1). Multiple studies have documented the principal distribution of adenohypophyseal cells in fish [61, 65-68] and amphibians [69-71]; the impact

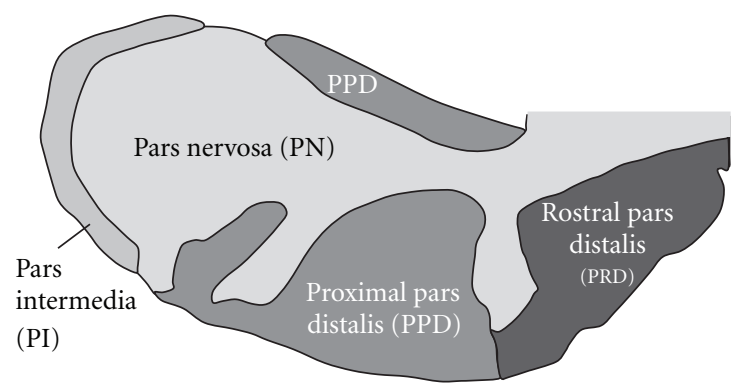

FIgURE 1: Sagittal view of zebrafish (Danio rerio) pituitary.

of thyroid-disrupting chemicals, however, has not been investigated so far.

The antithyroid drug, propylthiouracil (PTU) — a representative of the thionamide group-which contains a sulfhydryl group and a thiourea moiety within a heterocyclic structure, has been selected for its well-known mode of action on thyroid peroxidases. It inhibits the production of thyroid hormones by interfering with thyroid-peroxidasemediated iodination of tyrosine residues in thyroglobulin [72]. In contrast to mammals, PTU has no effect on fish deiodinases (D1, D2, and D3) [73-77]. In medical treatment, it is used for half a century to manage hyperthyroidism, especially Grave's disease [72, 78, 79]. The thyroid systemdisrupting effects of PTU observed in mammals have also been shown in other vertebrate groups, especially amphibians [21, 23, 80-82]. Effects of PTU on fish, however, have hardly been documented [41].

The present study was designed to identify histological and ultrastructural changes in selected zebrafish organs along the hypothalamic-pituitary-thyroid axis. Thus, histological endpoints in the thyroid, that is, distribution of the single follicles, hyperplasia, homogeneity of the follicles, colloid composition, hypertrophy, histological, and immunohistochemical identification of TSH-producing cells in the pituitary along with quantitative morphometrical evaluations, as well as histological and ultrastructural changes in the liver, as one of the main sites of deiodination, were examined.

\section{Material and Methods}

2.1. Animals and Husbandry. Fertilized eggs from zebrafish (Danio rerio) were obtained from in-house breeding facilities of the Aquatic Ecology and Toxicology Group at the Centre for Organismal Studies, University of Heidelberg. All experiments were conducted in compliance with the institutional guidelines for the care and use of animals as well as with permission by the regional animal welfare (AZ 35-9185.81/G-144/07). The exposure experiment involved aqueous exposure of 60 Danio rerio larvae for 5 weeks in two replicates. Fertilized eggs were initially raised in $20 \mathrm{~cm}$ Petri dishes in a KB 115 incubator (Binder, Tuttlingen, Germany) at a constant temperature of $27.0 \pm 1.0^{\circ} \mathrm{C}$, which had been preexposed to $0,2.5,10,25$, and $50 \mathrm{mg} / \mathrm{L}$ 6-propyl2-thiouracil (Sigma, Deisenhofen, Germany) for saturation. Three days after fertilization, the eggs were transferred into the $10 \mathrm{~L}$ flow-through exposure facilities (triplicate water 
change/d, $27.0 \pm 1.0^{\circ} \mathrm{C}, 12: 12 \mathrm{~h}$ light: dark cycle; oxygen saturation $>80 \%$ ) containing the same PTU concentrations. Flow-through conditions guaranteed that ammonia, nitrite, and nitrate were kept below detection limits $(0-5,0.025-1$ and $0-140 \mathrm{mg} / \mathrm{L}$, resp.). After hatching, embryos were fed daily with Sera Micron (Sera, Heinsberg, Germany) and after one week with freshly raised Artemia nauplii (Sanders, USA) ad libitum. Excessive food and feces was removed from the aquaria at least twice daily.

2.2. Histology. After 5 weeks, each of the 60 fish per concentration group was anesthetized with a saturated solution of 4-ethylaminobenzoate (benzocaine, Sigma). Whole body length and weight were measured immediately after anesthetization. For histology, thirty fish were fixed in Davidson's fixative [83] for a minimum of $24 \mathrm{hrs}$ at $4^{\circ} \mathrm{C}$. Whole fish were processed in a Leica TP 1020 Tissue Processor (Leica Microsystems, Wetzlar, Germany), embedded in Histoplast S (Serva, Heidelberg, Germany) and sectioned in horizontal and median planes at $2 \mu \mathrm{m}$ thickness, respectively. For details on embedding see Table 1. Serial sections of the thyroid, the pituitary, and liver region were mounted on glass slides covered with an albumin-glycerin solution (Serva), stained with PAS [83]; nuclei were counterstained with hematoxylin and coverslipped with X-TRA Kitt (Medite, Burgdorf, Germany).

2.3. Pituitary Immunohistochemistry. For immunohistochemistry, the Vectastain ABC Kit for the detection of TSH (Vector Laboratories, Burlingame, USA) was used in the control and the highest concentration group, respectively. During this procedure, antigens were unmasked by heating the slides to $96^{\circ} \mathrm{C}$ in $0.01 \mathrm{M}$ citrate buffer ( $\mathrm{pH}$ 6.0) followed by incubation in $1 \% \mathrm{H}_{2} \mathrm{O}_{2}$ in phosphate-buffered saline (PBS, pH 7.4). Unspecific binding was reduced by double blocking sections with (1) $2 \%$ bovine serum albumin in PBS for $30 \mathrm{~min}$ at room temperature and (2) the blocking serum delivered by Vector Laboratories. Afterwards, sections were incubated overnight at $4^{\circ} \mathrm{C}$ with a rabbit anti-human TSH antibody (AbDSerotec, Oxford, UK; cat. no. 89260004) diluted 1:250 in PBS. After three rinses in PBS, the antiserum was tagged with the biotinylated Vectastain secondary antibody and then incubated in a preformed avidin and biotinylated horseradish peroxidase complex. To visualize the antiserum, sections were incubated in 3,3'-diaminobenzidine (Vector Laboratories) until desired staining intensities had developed. According to the manufacturer, the antiserum reacts with fish. The specificity had been shown previously by Grandi and Chicca [84] in Acipenser naccarii and by Kasper et al. [61] in Oreochromis niloticus. For instance, no immunostaining was observed after preincubation of the antihuman $\beta$-TSH antisera with an excess of the appropriate antigens [84]. Sections were slightly counterstained with Mayer's hematoxylin [83], rehydrated, and mounted for observation.

2.4. Ultrastructure. For ultrastructural studies, liver samples were fixed in $2.5 \%$ glutardialdehyde in sodium cacodylate buffer ( $\mathrm{pH} 7.4$ ) at $4^{\circ} \mathrm{C}$ for a minimum of $24 \mathrm{hrs}$ and
TABLE 1: Details of dehydration and embedding of zebrafish tissue.

\begin{tabular}{lc}
\hline Dehydration & Duration \\
\hline $80 \%$ ethanol & $1 \mathrm{~h}$ \\
$90 \%$ ethanol & $1 \mathrm{~h}$ \\
$90 \%$ ethanol & $1 \mathrm{~h}$ \\
$96 \%$ ethanol & $1 \mathrm{~h}$ \\
$96 \%$ ethanol & $1 \mathrm{~h}$ \\
$100 \%$ isopropanol & $1 \mathrm{~h}$ \\
$100 \%$ isopropanol & $1 \mathrm{~h}$ \\
Xylene & $1 \mathrm{~h}$ \\
Xylene & $12 \mathrm{~h}$ \\
Xylene & $4 \mathrm{~h}$ \\
Histoplast S & $12 \mathrm{~h}$ \\
Histoplast S & $12 \mathrm{~h}$ \\
\hline
\end{tabular}

postfixed with $1 \%$ osmium ferrocyanide for two hours [85]. After triplicate rinsing in sodium cacodylate buffer $(\mathrm{pH}$ 7.4), tissues were stained en bloc with $1 \%$ uranyl acetate in maleic buffer ( $\mathrm{pH} 5.2$ ) overnight at $4^{\circ} \mathrm{C}$. The liver was dehydrated in a graded series of ethanol and embedded in Spurr's medium [86]. For localization of correct sectioning areas, semithin sections were cut on a Reichert-Jung Ultracut microtome (Leica Microsystems) and stained with methylene blue/Azur II [87]. Afterwards, ultrathin sections of 60-80 nm were cut and counterstained with alkaline lead citrate [88].

2.5. Imaging. For both histology and immunohistochemistry, light microscopy was performed with a Leitz Aristoplan microscope (Leitz, Wetzlar, Germany) equipped with a ColorView Soft Imaging Systems digital camera (Soft Imaging Systems, Münster, Germany). The surface areas of adeno-, neurohypophysis, and total pituitary were measured and the number of TSH-producing cells counted using the free software tool Image J 1.44 (National Institutes of Health, USA) to quantify the observed alterations. Ultrathin sections of the liver were examined in a Zeiss EM 10C (Carl Zeiss, Oberkochen, Germany) transmission electron microscope.

2.6. Thyroid Hormone Extraction and ELISA. The methods for methanol extraction of whole body THs were adopted from Shi et al. [17] in zebrafish. Three zebrafish samples from each concentration group were homogenized in $0.5 \mathrm{~mL}$ ice-cold methanol with $1 \mathrm{mM}$ PTU. The homogenates were dispersed by intermittent sonic oscillation for $5 \mathrm{~min}$ on ice and vortexed for $10 \mathrm{~min}$. After centrifugation at 3,500 g at $4^{\circ} \mathrm{C}$ for $20 \mathrm{~min}$, the supernatants were collected, and the pellets were re-extracted with $0.5 \mathrm{~mL}$ ice-cold methanol/PTU and centrifuged again. The freshly collected supernatant was combined with the original supernatant and vacuum dried overnight at room temperature. The samples were redissolved in $0.05 \mathrm{~mL}$ methanol, $0.2 \mathrm{~mL}$ chloroform, and $0.05 \mathrm{~mL} 0.11 \mathrm{M}$ barbital buffer ( $\mathrm{pH}$ 8.6; Sigma). The mixture was vortexed for $3 \mathrm{~min}$ and centrifuged at $3,500 \mathrm{~g}$ at $4^{\circ} \mathrm{C}$ for $15 \mathrm{~min}$. The upper layer was carefully collected and immediately used for the T4 measurements. The ELISA 
was performed with commercial kits (Diagnostic Automation/Cortez Diagnostics Inc., Calabasas, USA) according to the manufacturer's instructions.

2.7. Data Analysis. The nonparametric Kruskal-Wallis test was used to determine differences in whole body weight and length, T4 content, and the surface areas of the pituitary. 60 fish of each concentration group were used to determine whole body length, weight, and the surface areas of the pituitary. T4 content was measured in three animals per concentration group. Dunn's multiple comparison test was used for pairwise comparisons with the control group. For analyzing TSH-producing cell number the Mann-Whitney test was used to compare 5 individuals from the highest concentration group to 5 individuals from the control. All statistical analyses were performed using the software package GraphPad Prism 4.0a for Macintosh (GraphPad Software, Inc., La Jolla, USA). Differences were considered significant at $* P<0.05$, highly significant at $* * P<0.01$, and highest significant at $* * * P<0.001$.

\section{Results}

3.1. Whole Body Weight and Whole Body Length. Both whole body weight and length showed a biphasic response pattern to PTU exposure (Figure 2). If compared to the control group, a statistically significant decrease in whole body length was observed in fish exposed to $50 \mathrm{mg} / \mathrm{L}$ PTU. In contrast, mean values for whole body length from zebrafish treated with 2.5 and $10 \mathrm{mg} / \mathrm{L}$ were slightly higher than in control fish, with $25 \mathrm{mg} / \mathrm{L}$ reaching the control level again. Nevertheless, none of the observed increases in the lower concentrations showed any statistical significance. Whole body weight revealed a similar pattern with an increase at the low concentrations and a slight decrease at the highest concentration. However, in contrast to whole body length, a statistically significant increase in fish exposed to $2.5 \mathrm{mg} / \mathrm{L}$ PTU was observed, whereas the highest concentration only showed a slight, but nonsignificant decrease.

3.2. T4 Contents. ELISA measurements of T4 contents revealed a dose-dependent decrease of T4 with a significant reduction in the $50 \mathrm{mg} / \mathrm{L}$ concentration group (Figure 3 ). Probably due to the small sample size of only three fish per treatment group, the $50 \mathrm{mg} / \mathrm{L}$ group was the only significant group compared to the control despite the dose-response curve.

3.3. Macroscopical Effects. From $10 \mathrm{mg} / \mathrm{L}$ PTU, clear macroscopical effects could be observed. The opercular region showed increasing red coloration due to massive blood aggregation. Furthermore, fish exposed to concentrations $\geq 25 \mathrm{mg} / \mathrm{L}$ displayed obvious goiter formations in the midline of the lower jaw region. Concomitant to the blood aggregation in the opercular region, the goiters displayed a clear red coloration resulting from massive blood aggregations (Figure 4).

3.4. Histological Alterations in the Thyroid. PTU-related effects in the thyroid are summarized in Table 2. Light
TABLE 2: Semiquantitative evaluation of alterations in the thyroid of zebrafish (Danio rerio) induced by PTU.

\begin{tabular}{|c|c|c|c|c|c|}
\hline PTU (mg/L) & Control & 2.5 & 10 & 25 & 50 \\
\hline \multicolumn{6}{|l|}{ Follicles } \\
\hline Total number & & + & ++ & +++ & +++ \\
\hline Size & & + & + & +++ & +++ \\
\hline Shape & & & ++ & +++ & ++++ \\
\hline \multicolumn{6}{|l|}{ Blood vessels } \\
\hline Hyperemia & & & ++ & +++ & ++++ \\
\hline \multicolumn{6}{|l|}{ Colloid } \\
\hline Reduced homogeneity & & & + & +++ & ++ \\
\hline Reduced density & & & + & +++ & ++ \\
\hline Colloid depletion & + & + & + & + & + \\
\hline Foamy texture & & & & + & + \\
\hline Cellular inclusions & & & & ++ & ++ \\
\hline \multicolumn{6}{|l|}{ Epithelial cells } \\
\hline Cell height & & & ++ & +++ & +++ \\
\hline Stratification & & & & ++ & +++ \\
\hline Cell crowding & & & + & ++ & +++ \\
\hline
\end{tabular}

Data are given as means of observation in 20 individuals per exposure group: ${ }^{+}$little developed; ${ }^{++}$moderately developed; ${ }^{+++}$strongly developed; ${ }^{++++}$very strongly developed.

microscopical examination of thyroidal tissue exposed to PTU revealed complex dose-dependent effects. Whereas in the control group the spherically to ovally shaped thyroid follicles, consisting of cuboid to flat epithelia surrounding a homogeneously stained colloid, were loosely distributed in the connective tissue adjacent to the ventral aorta and its final rostral branching in the gill region (Figures 5(a) and 5(b)), the PTU-exposed groups showed conspicuous deteriorations (Figure 6).

3.4.1. Follicles. From the lowest PTU concentration, increasing numbers of thyroid follicles and, to lower extent, proliferations of follicle size were detectable (Figure 6(a)). Both effects were strongest in concentration groups $\geq 25 \mathrm{mg} / \mathrm{L}$, but could already be observed at $2.5 \mathrm{mg} / \mathrm{L}$ with a dosedependent increase. Following exposure to concentrations $\geq 2.5 \mathrm{mg} / \mathrm{L}$ PTU, follicle shape changed, with an increase in the numbers of papillary in- and outfoldings. In terms of histology, the above-mentioned goiter observed at concentrations $\geq 25 \mathrm{mg} / \mathrm{L}$ PTU consisted of numerous small follicles and connective tissue embedded in an enlarged capillary network responsible for the red coloration already observed macroscopically. Although there were hardly any goiters visible at $10 \mathrm{mg} / \mathrm{L}$, histologically detectable goitrous tissue was detectable from $10 \mathrm{mg} / \mathrm{L}$ PTU. The most conspicuous structural modification was the appearance of follicles in the gills, which was detectable at concentrations $\geq 10 \mathrm{mg} / \mathrm{L}$ (Figure 6(f)). In contrast, at $2.5 \mathrm{mg} / \mathrm{L}$, follicles were randomly distributed, but restricted to the pharyngeal region.

3.4.2. Architecture of the Blood Vessel Supply. One of the most striking effects was the architecture of the blood vessels surrounding the thyroid follicles. From concentrations 


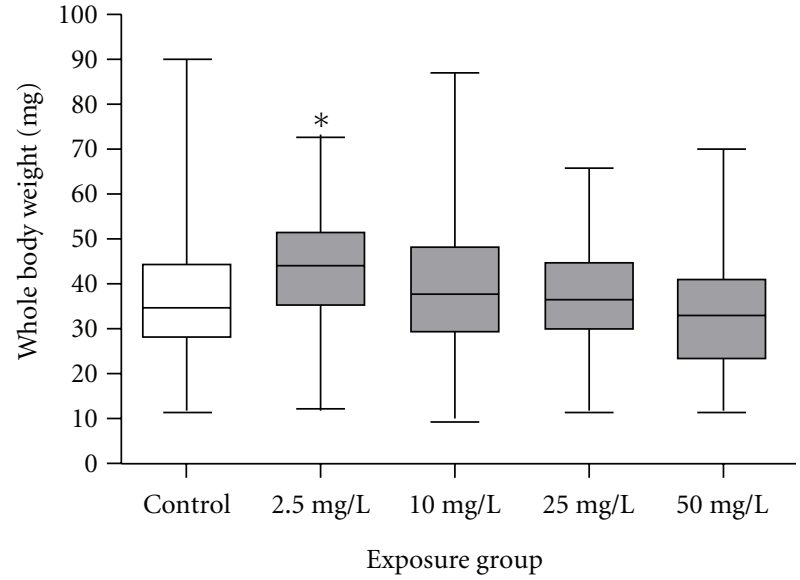

(a)

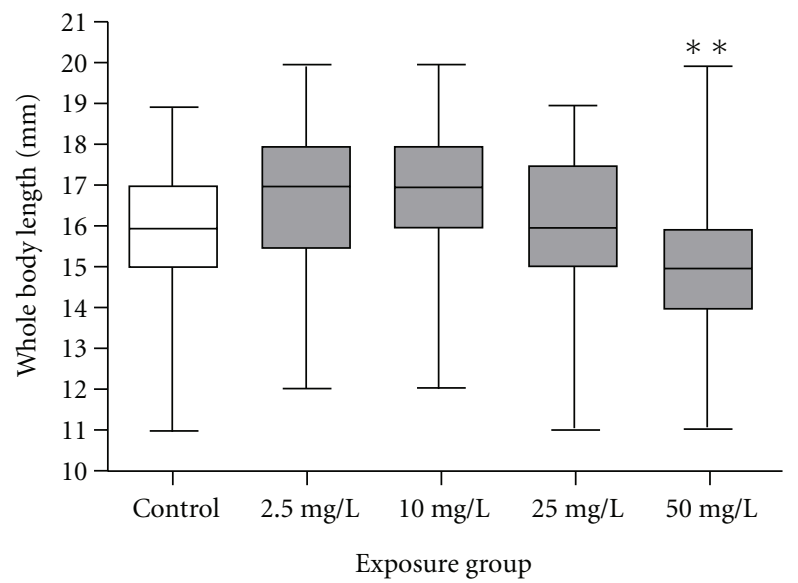

(b)

FIgURE 2: Whole body weight and length of zebrafish (Danio rerio) after exposure to $0,2.5,10,25$, and $50 \mathrm{mg} / \mathrm{L}$ PTU. Measurements were performed with 60 animals after 35 days of exposure. Asterisks indicate significant differences between exposure and control groups ( ${ }^{*} P<0.05,{ }^{* *} P<0.01$; Dunn's test $)$.

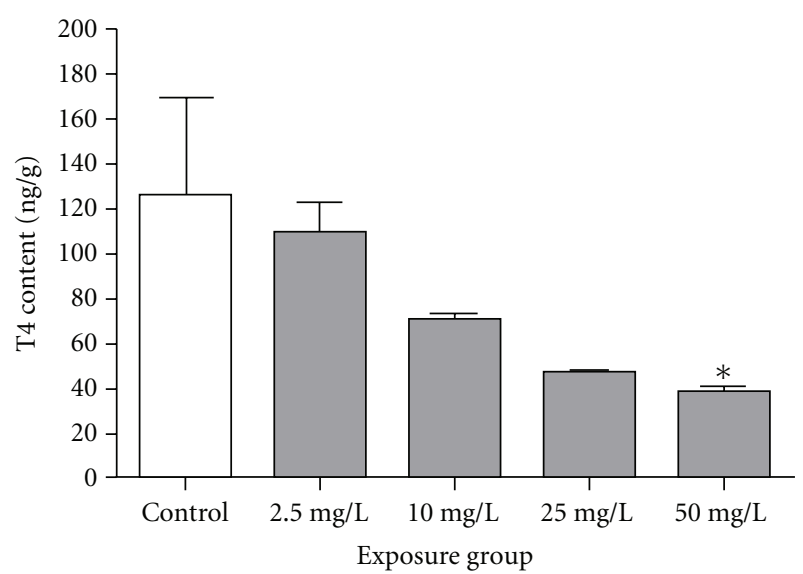

Figure 3: Whole body contents of T4 in zebrafish (Danio rerio) exposed to $0,2.5,10,25$, and $50 \mathrm{mg} / \mathrm{L}$ PTU. Results are given as means \pm SEM from three samples per replicate. Asterisks indicate significant differences between exposure and control groups $\left({ }^{*} P<\right.$ 0.05; Dunn's test).

$\geq 2.5 \mathrm{mg} / \mathrm{L}$, a concentration-dependent proliferation of the adjacent blood vessels was evident with massive hyperemia at $\geq 25 \mathrm{mg} / \mathrm{L}$ (Figures 6(a) and 6(b)). These observations are in line with the macroscopically detected coloration of the entire opercular region.

3.4.3. Alterations in Colloid Appearance. Whereas colloid homogeneity and colloid density/contents were only slightly modified in single individuals at the lowest concentration, there were clear-cut alterations in exposure groups $\geq 10 \mathrm{mg} / \mathrm{L}$ : in contrast to the controls and the lowest concentration, PAS-staining revealed a blotchy and foamy texture with heterogeneous tinctorial properties. Throughout all experimental groups, colloid depletion could be detected, however, not in a dose-dependent manner. From $10 \mathrm{mg} / \mathrm{L}$, an increased number of cellular inclusions was visible in the colloid of several individuals (Figure 6(c)). Shrinking phenomena were evident in all experimental groups and should not be misinterpreted as effects by PTU.

3.4.4. Alterations of Epithelial Cells. As in controls, epithelial cells in individuals exposed to $2.5 \mathrm{mg} / \mathrm{L}$ PTU displayed a cuboid to flat appearance with only few exceptions showing a slight increase in cell height resulting in a moderately columnar appearance. At concentrations $\geq 10 \mathrm{mg} / \mathrm{L}$, epithelial cell height consistently increased to a columnar cell shape with stratification and cell crowding (Figure 6(d)). The nucleus, centrally located in cuboidal cells, migrated towards the basal part of the columnar-shaped thyrocytes. At $25 \mathrm{mg} / \mathrm{L}$ and $50 \mathrm{mg} / \mathrm{L}$ PTU, an increasing number of individuals showed large vesicles in the apical part of the cell (Figure 6(e)).

\subsubsection{Histological and Immunohistochemical Alterations in} the Pituitary. On consecutive PAS-stained control sections, a clear separation of the neurohypophysis from the adenohypophysis was visible with the neurohypophysis slightly digitating into the adenohypophysis (Figure 7(a)). With respect to overall dimensions of the pituitary on longitudinal sections across the pituitary, only the $25 \mathrm{mg} / \mathrm{L}$ PTU concentration group revealed a statistically significant increase of pituitary surface area in consequence of PTU exposure (Figure 8). As a member of the glycoprotein family, TSH, together with FSH and $\mathrm{LH}$, reacted PAS-positive and could be detected in the proximal pars distalis along the border to the pars nervosa, which digitated into the adenohypophysis. Although differentiation of TSH-producing cells from FSH- and LH-producing cells was not possible with PAS staining, profound morphological changes in consequence of exposure to PTU could already be detected in PAS-stained sections. Especially at 25 and $50 \mathrm{mg} / \mathrm{L}$ PTU exposure, a clear proliferation of adenohypophyseal tissue was visible (Figure 7(b)). Morphometrical analysis revealed a significant 

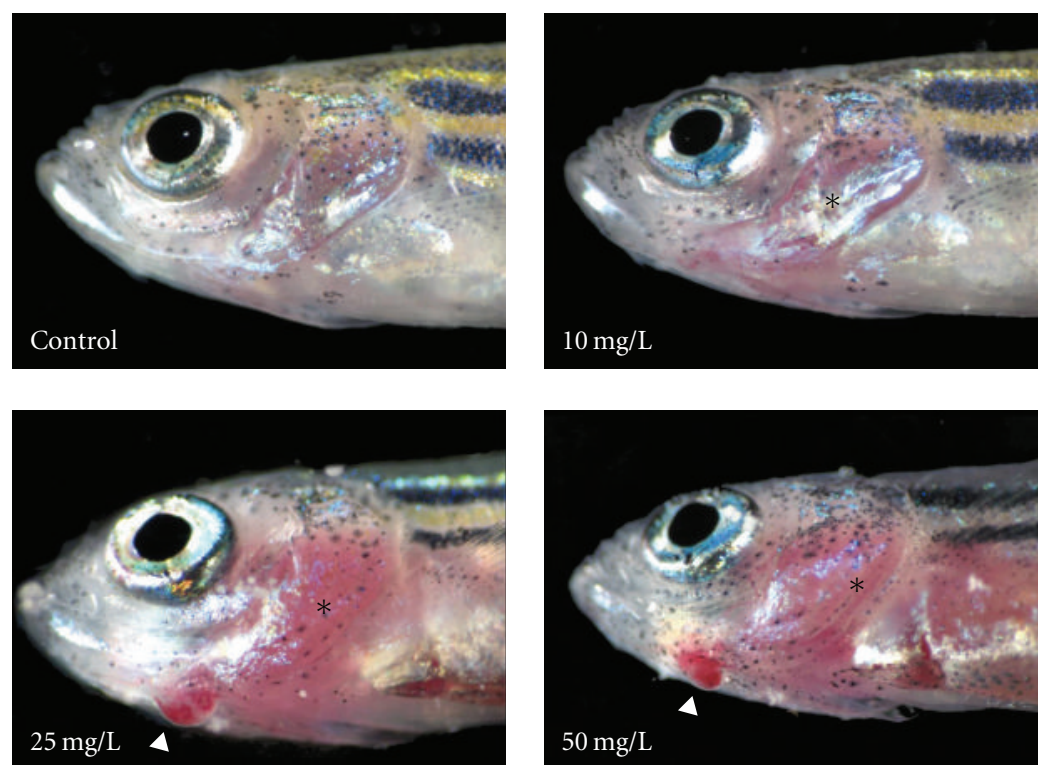

FIGURE 4: Representative macroscopical pictures of the head region of zebrafish (Danio rerio) following exposure to 0, 10, 25, and 50 mg/L PTU. Increased red coloration due to blood aggregation in the opercular region $(*)$ at concentrations $\geq 10 \mathrm{mg} / \mathrm{L}$ and goiter formation $(\triangle)$ at concentrations $\geq 25 \mathrm{mg} / \mathrm{L}$ are clearly detectable.

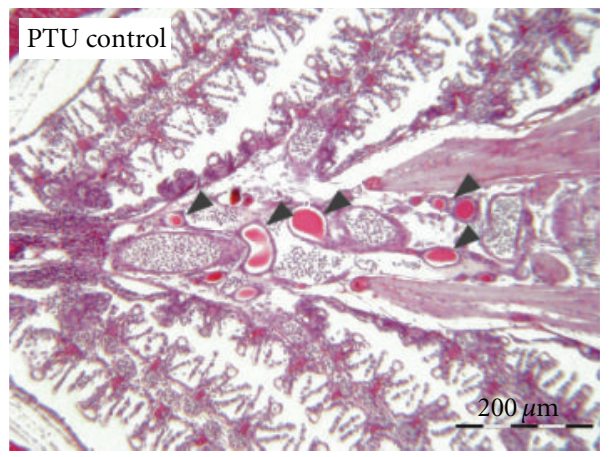

(a)

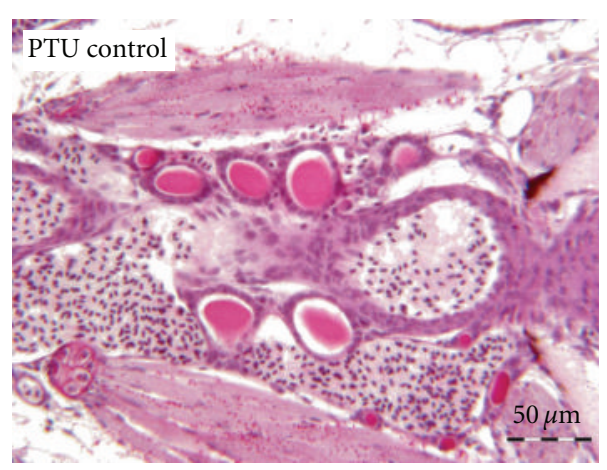

(b)

FIgURE 5: Representative histological pictures of thyroidal tissue in the control zebrafish (Danio rerio). The isolated thyroid follicles are distributed adjacent to the ventral aorta in the gill region. Follicular shape is spherical to oval with a cuboidal epithelium and a homogeneously stained colloid. Sections of $2 \mu \mathrm{m}$ thickness stained with periodic acid-Schiff (PAS) and Mayer's hematoxylin.

increase in adenohypophyseal tissue in the two highest concentration groups (Figure 8). This proliferation mostly occurred in the proximal pars distalis of the adenohypophysis (Figure 7(b)). Thus, given the similar pituitary volumes of control and exposed fish, the ratio between adeno- and neurohypophysis had changed (Figure 9). PTU led to a clear dose-dependent increase of this ratio with significant changes from $10 \mathrm{mg} / \mathrm{L}$ onwards. Surface area measurements of the neurohypophysis did not reveal any significant proliferations (Figure 8).

Immunohistochemical staining with anti-TSH antibodies revealed a rather homogeneous distribution of TSHproducing cells (Figure 10). In the control group, TSHpositive cells were mainly limited to the rostral pars distalis and the pars intermedia with a few cells located in the proximal pars distalis (Figure 10(a)). This situation changed after exposure to $50 \mathrm{mg} / \mathrm{L}$ PTU (Figure 10(b)): the most striking proliferation occurred in the proximal pars distalis, where cells located at the border of the proximal pars distalis to the pars nervosa proliferated. This observation is in line with the aforementioned proliferation of adenohypophyseal tissue. Quantification of TSH-producing cell counts in the control and the highest concentration group led to a statistically significant increase after exposure to PTU (Figure 11).

3.4.6. Further Histological and Ultrastructural Alterations in the Liver. PTU-related effects in the liver are summarized in Table 3. Histologically, these alterations by PTU were restricted to a moderate depletion of glycogen deposits, which was concentration dependent up to the highest concentration group of $50 \mathrm{mg} / \mathrm{L}$ (Figure 12). Interestingly, at concentrations $\geq 25 \mathrm{mg} / \mathrm{L}$ the numbers of mitochondria 


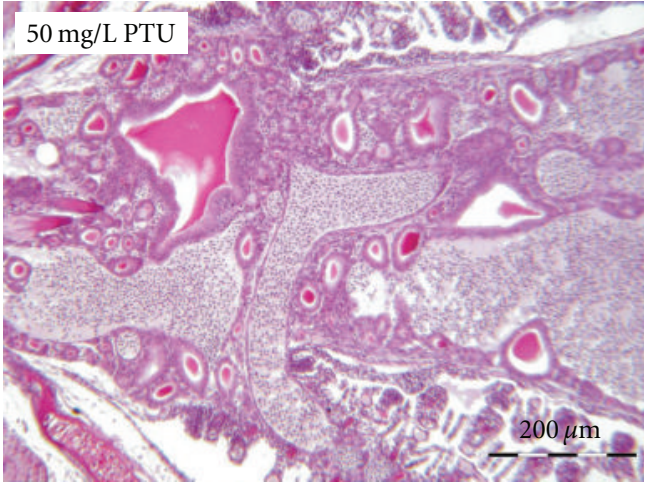

(a)

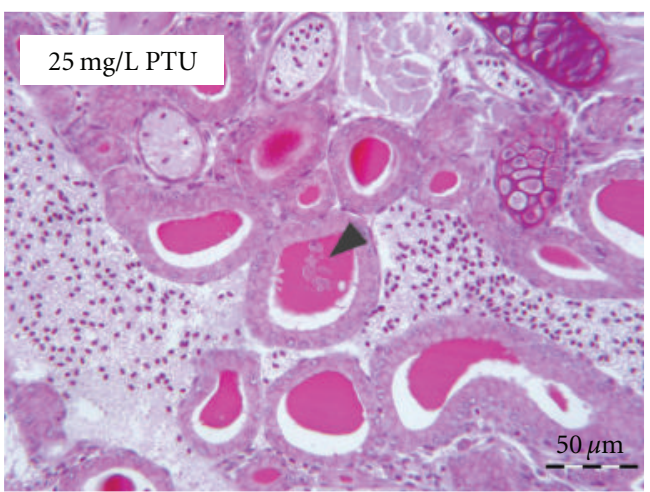

(c)

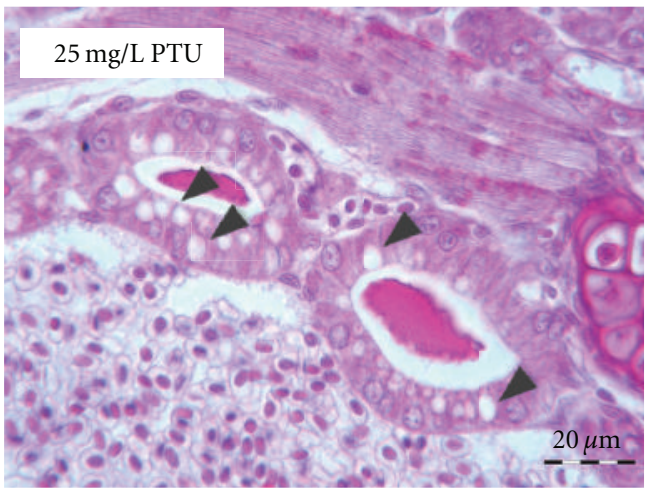

(e)

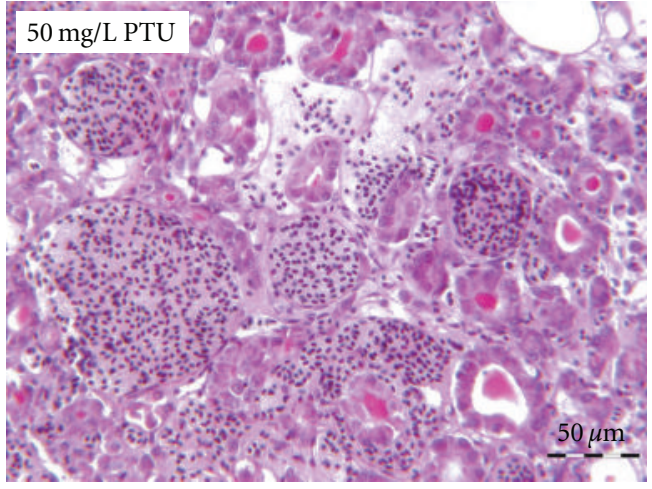

(b)

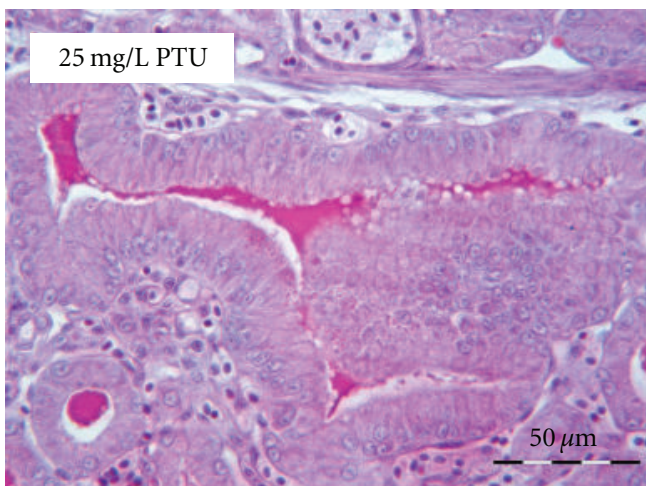

(d)

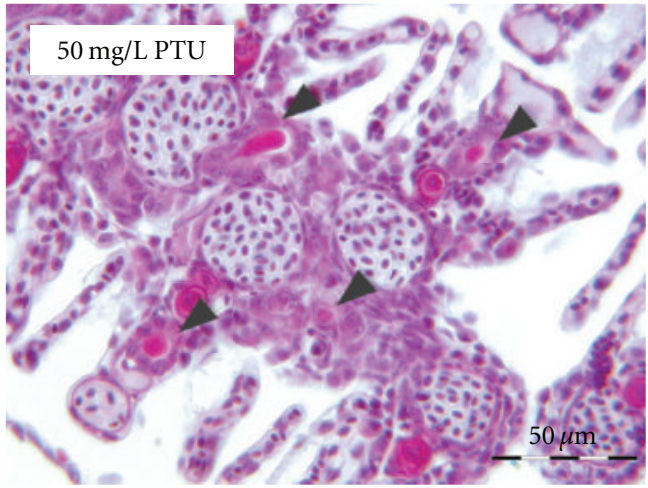

(f)

FIgURE 6: Representative histopathological effects in thyroidal tissue of zebrafish (Danio rerio) exposed to 25 and $50 \mathrm{mg} / \mathrm{L}$ PTU. Exposure to PTU resulted in massive hyperplasia and hyperemia with an increased number of small follicles embedded in adjacent blood capillaries (a, b). In the 25 and $50 \mathrm{mg} / \mathrm{L}$ concentration groups, inclusion bodies in the colloid were visible ((c): $\mathbf{\Delta})$. At concentrations $\geq 10 \mathrm{mg} / \mathrm{L}$, severe hypertrophy of thyroid follicles could be detected with stratification and cell crowding (d): One individual in each of the 25 and $50 \mathrm{mg} / \mathrm{L}$ concentration groups showed mostly apically located vesicles in the epithelial cells ((e): $\mathbf{\Delta})$. Some individuals displayed small follicles scattered across the gills ((f): $\mathbf{\Delta})$. Sections of $2 \mu \mathrm{m}$ thickness stained with periodic acid-Schiff (PAS) and Mayer's hematoxylin.

decreased. Following exposure to PTU, the rough endoplasmic reticulum of zebrafish underwent a moderate reduction and displayed some fenestration (Figure 13).

\section{Discussion}

In the present study, histological, immunohistochemical, and ultrastructural alterations of the thyroid, the pituitary, and the liver in the zebrafish by the potent antithyroid drug PTU were evaluated in order (1) to reveal reactions of the thyroid system to potential endocrine-disrupting chemicals, (2) to determine the sensitivity of the zebrafish thyroid system to endocrine-disrupting chemicals, and (3) to investigate changes in the pituitary as the main control organ of the endocrine system.

The evaluation of suitable endpoints is highly linked with the understanding of the underlying regulating endocrinological mechanisms and the mode of action of the test 
TABLE 3: Semiquantitative evaluation of alterations in the liver of zebrafish (Danio rerio) induced by PTU.

\begin{tabular}{|c|c|c|c|c|c|}
\hline PTU (mg/L) & Control & 2.5 & 10 & 25 & 50 \\
\hline \multicolumn{6}{|l|}{ Glycogen } \\
\hline Glycogen depletion & + & + & ++ & ++ & ++ \\
\hline \multicolumn{6}{|l|}{ Mitochondria } \\
\hline Decrease in number & & & + & ++ & ++ \\
\hline \multicolumn{6}{|c|}{ Rough endoplasmic reticulum } \\
\hline Fenestration & & & + & ++ & ++ \\
\hline Reduction in amount & & & + & ++ & ++ \\
\hline
\end{tabular}

Data are given as means of observation in 10 individuals per exposure group: ${ }^{+}$little developed; ${ }^{++}$moderately developed; ${ }^{+++}$strongly developed; ${ }^{+++}$very strongly developed.

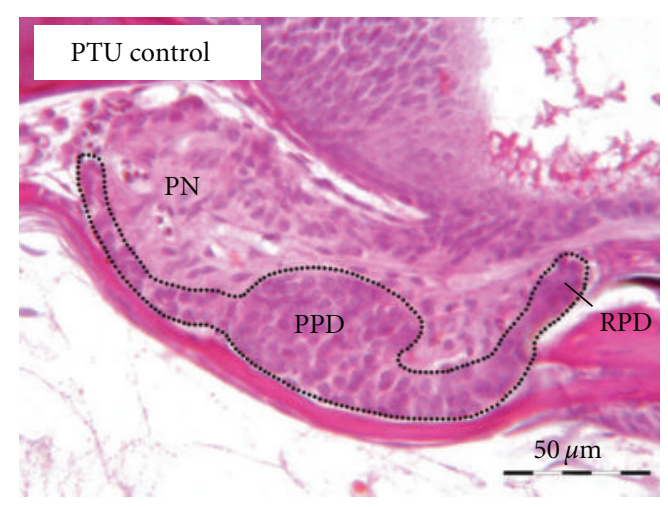

(a)

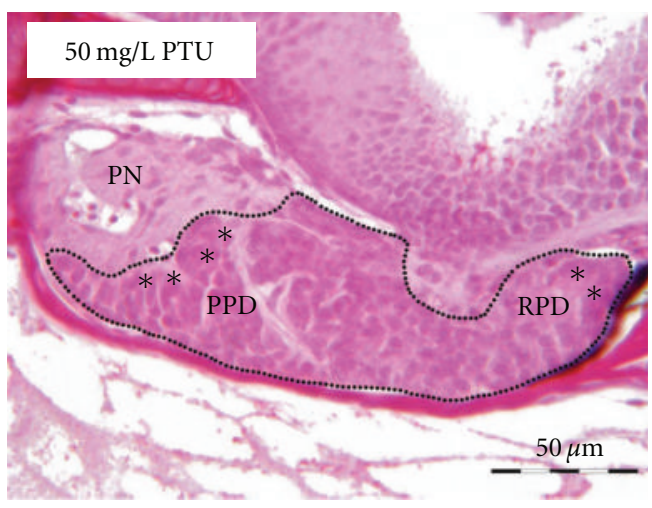

(b)

FIgURE 7: Representative PAS-stained sagittal sections of zebrafish (Danio rerio) pituitaries exposed to PTU. The adenohypophysis is encircled by a dotted line to highlight the changes in the ratio between adeno- and neurohypophysis. A massive proliferation of PASpositive cells $(*)$ mostly located in the proximal pars distalis is evident. PI-pars intermedia (adenohypophysis); PN—pars nervosa (neurohypophysis); PPD—proximal pars distalis (adenohypophysis); RPD—rostral pars distalis (adenohypophysis). Sections of $2 \mu \mathrm{m}$ thickness stained with periodic acid-Schiff (PAS) and Mayer's hematoxylin.

substance. For the interpretation of effects by thyroid systemdisrupting chemicals, it is indispensible to understand the different endpoints, since these endpoints might also provide indications as to the underlying mode of action. Out of the numerous possibilities for disruption along the hypothalamic-pituitary-thyroid axis, PTU inhibits thyroid hormone synthesis by interfering with thyroid-peroxidasemediated iodination of tyrosine residues in thyroglobulin [72]. In teleost fish, the hypothalamic-pituitary-thyroid axis is regulated by feedback mechanisms, but the critical step in the synthesis of the biologically active hormone T3 is located in peripheral tissues, mainly the liver. This aspect has to be taken into account, when judging thyroid system-disrupting chemicals.

Gross morphology of zebrafish exposed to PTU revealed striking effects in the thyroid and associated tissues with massive effects in the supporting blood vessels. The proliferation observed for adjacent blood vessels led to severe hyperemia at concentrations $\geq 25 \mathrm{mg} / \mathrm{L}$. This effect was most prominent in goitrous tissue, where the connection between follicles and supporting blood vessels was highly evident. Connors et al. [89, 90] reported correlations between TSH concentration and thyroid gland blood flow in rats. Although
TSH-concentrations were not measured in the present study, immunohistological staining of TSH-producing cells in pituitaries of the highest concentration group revealed a significant increase of these cells indicating an elevation of TSH concentrations. As a consequence, the effects observed in the present study would be caused by elevated TSH concentrations caused by the negative feedback in the hypothalamic-pituitary-thyroid axis due to the exposure to PTU.

Hyperplasia and hypertrophy are two alternatives to accomplish thyroid activation in various species $[70,80$, $91,92]$. In this study, hyperplasia of thyroidal tissue was most sensitive and most prominent from the lowest PTU concentration. In contrast, thyreocyte hypertrophy was only detectable at concentrations $\geq 10 \mathrm{mg} / \mathrm{L}$. Thus, at least in juvenile fish, the first step to upregulate $\mathrm{TH}$ production via TSH seems to be an increase in cell number (hyperplasia) rather than an increase in cell size (hypertrophy). TSH production is under the negative feedback influence of both T4 and T3 $[48,93]$. The activating effect of TSH is mediated via a G-protein-coupled TSH-receptor [94], which is mainly expressed in thyroidal tissue and the gonads [95]. Nevertheless, the factors that trigger hyperplasia remain unclear and 


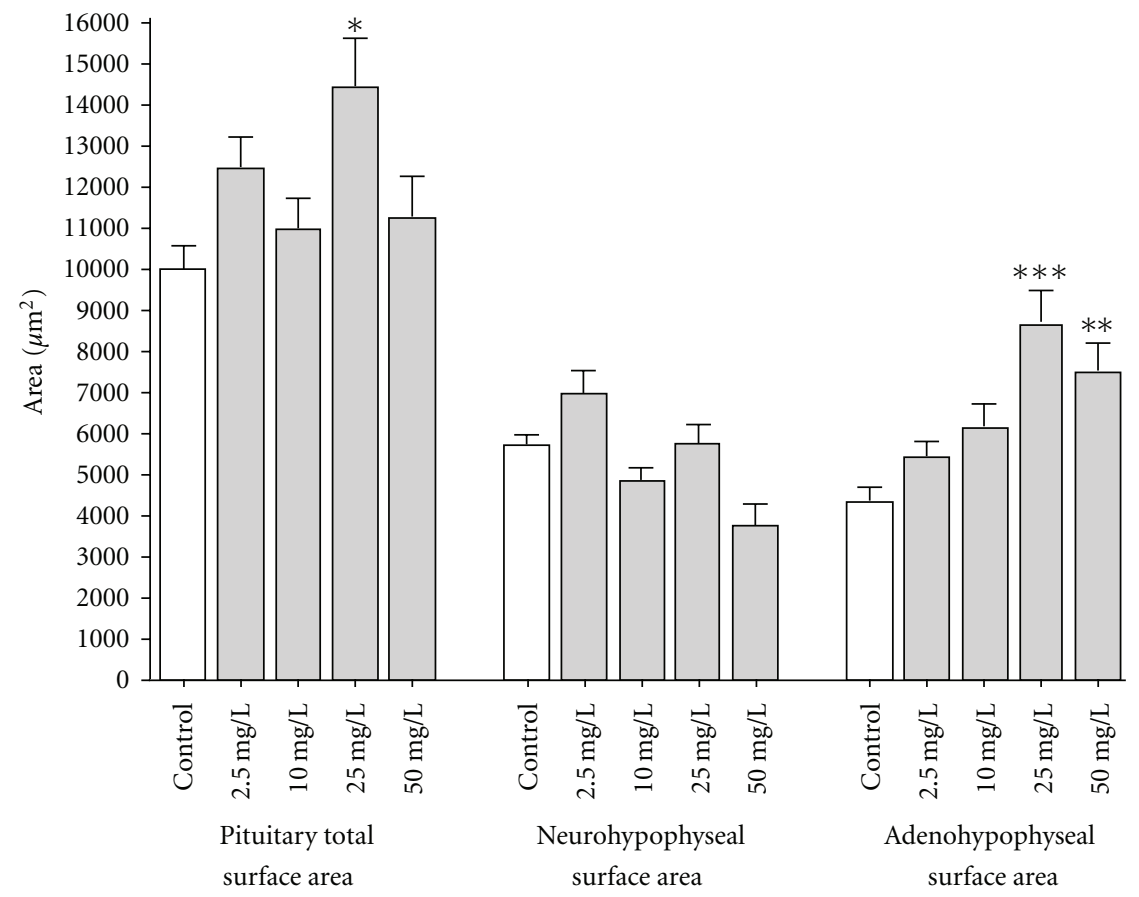

Figure 8: Pituitary surface areas of zebrafish (Danio rerio) after exposure to 0, 2.5, 10, 25, and $50 \mathrm{mg} / \mathrm{L}$ PTU. Measurements were performed with 60 animals after 35 days of exposure. Asterisks indicate significant differences between exposure and control groups $\left({ }^{*} P<0.05\right.$, ${ }^{* *} P<$ $0.01,{ }^{* * *} P<0.001$; Dunn's test).

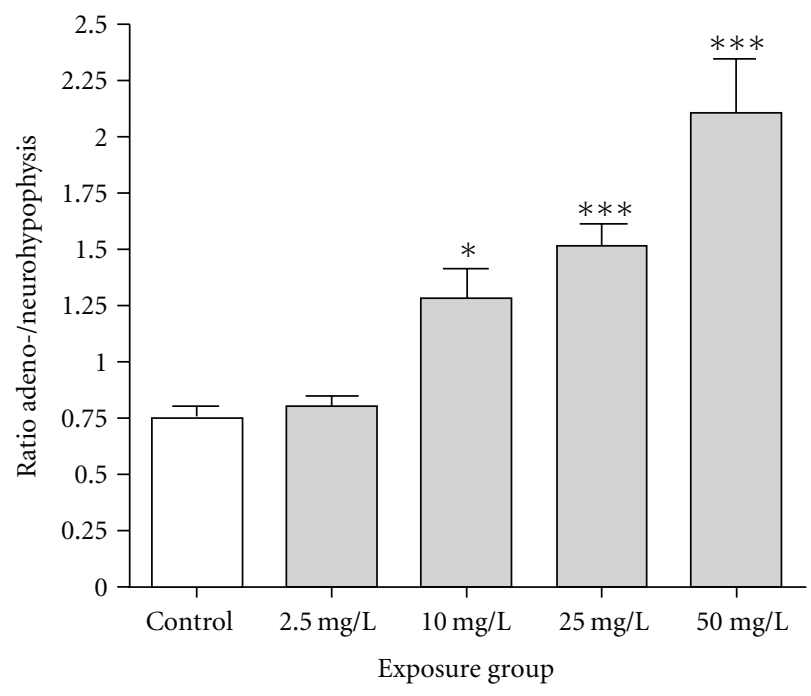

Figure 9: Ratio of adeno- to neurohypophyseal tissue of zebrafish (Danio rerio) after exposure to $0,2.5,10,25$, and $50 \mathrm{mg} / \mathrm{L}$ PTU. Measurements were performed with 60 animals after 35 days of exposure. Asterisks indicate significant differences between exposure and control groups $\left({ }^{*} P<0.05,{ }^{* * *} P<0.001\right.$; Dunn's test).

need further exploration. The proliferation of the follicles was most prominent at concentrations $\geq 25 \mathrm{mg} / \mathrm{L}$, where several small follicles could be detected in the gills. Limited space in the central pharyngeal region and increasing demand for THs could lead to an invasion of thyroid tissues into the gills. Together with this invasion, a proximal swelling of the supporting blood vessels was detected. Although gill tissues seemed not to be effected per se, a displacement was obvious, leading to the question whether reduced functionality of gill tissues could lead to any respiratory consequences for the fish. In the present study, no signs of respiratory problems could be detected, but oxygen concentration in the tanks was kept near saturation throughout the experiment. There are studies demonstrating that fish are capable of surviving oxygen rates of $5 \%$ when acclimated to nonlethal oxygen concentrations $[96,97]$ showing numerous adaptions, for example, metabolic rate reduction or increased ventilation rates, hematocrit and hemoglobin oxygen affinity, which was detected in common sole (Solea solea) [98, 99].

A very interesting endpoint was the observation of changes in the quality of the colloid. As the main site of $\mathrm{TH}$ synthesis and storage, it was likely to detect alterations especially with PTU inhibiting thyroid peroxidases in the colloid itself. In the present study, PAS staining was used because of the special staining properties of the colloid, although standard HE staining is adequate to detect alterations in the colloid as documented in other publications $[19,39,100]$. In contrast to studies with perchlorate $[37,39$, 100], colloid depletion could not be identified as a significant PTU-induced effect. Partially or totally depleted follicles were present in each exposure group including the control, although complete depletion could never be observed in this study. Apparently, the different inhibiting mechanisms of perchlorate and PTU lead to distinct histological effects. Nevertheless, concentrations $\geq 10 \mathrm{mg} / \mathrm{L}$ led to clear-cut alterations in colloid homogeneity and density, and from $25 \mathrm{mg} / \mathrm{L}$ a foamy, granular texture was well visible in contrast to 


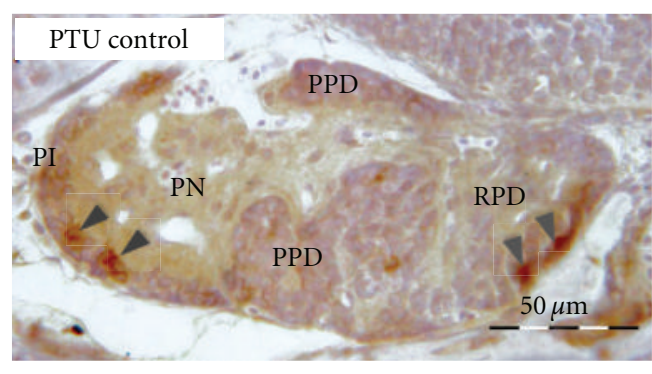

(a)

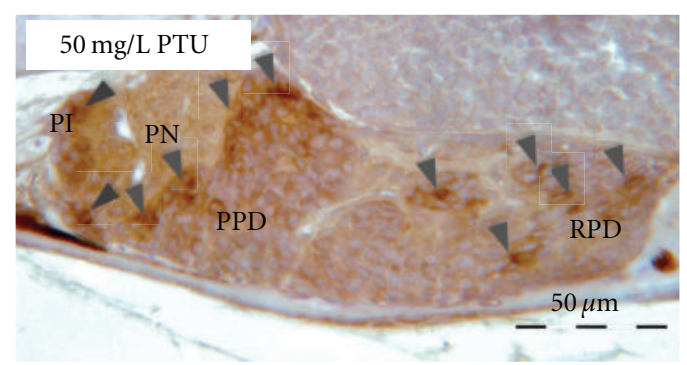

(b)

FIgURE 10: Sagittal sections of immunohistochemically stained zebrafish (Danio rerio) pituitaries exposed to 0 and 50 mg/L PTU. The samples show clear proliferations of TSH-producing cells $(\boldsymbol{\Delta})$ especially in the proximal pars distalis. Sections of $2 \mu \mathrm{m}$ thickness immunostained with an anti-TSH antibody (nuclei were counterstained with Mayer's hematoxylin). PI—pars intermedia (adenohypophysis); PN—pars nervosa (neurohypophysis); PPD—proximal pars distalis (adenohypophysis); RPD—rostral pars distalis (adenohypophysis).

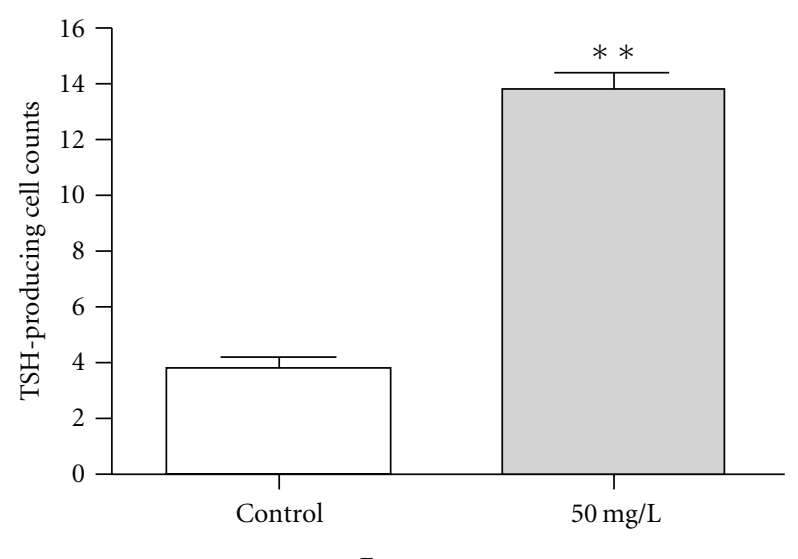

Exposure group

FIGURE 11: TSH-producing cell counts of zebrafish (Danio rerio) pituitaries after exposure to 0 and $50 \mathrm{mg} / \mathrm{L}$ PTU. Statistical analysis was conducted on five immunostained sections, respectively $\left({ }^{* *} P<\right.$ 0.01; Mann-Whitney test).

the homogenous, smooth texture in controls. Studies from Anderberg et al. [101, 102] on human thyroids revealed that the colloid is composed of $19 \mathrm{~S}$ thyroglobulin, larger iodoproteins, and smaller protein fractions (an albuminlike protein and a prealbumin fraction). In these studies, exposure to carbimazole, which belongs to the same group of chemicals as PTU, leads to a decrease of the larger thyroglobulin aggregates compared with the relative amount observed in the colloid from normal human thyroid tissue. This decrease was explained with an insufficient capacity to iodinate thyroglobulin. Such assumptions, could provide an explanation for the different staining properties and the granular texture observed in the exposure groups. Opitz et al. [81] described peripheral vacuolation in ethylenethioureaexposed Xenopus laevis tadpoles as a sign for activated follicles. This effect was hardly visible in the present study; however, at concentrations $\geq 25 \mathrm{mg} / \mathrm{L}$ cellular inclusions probably due to cellular blebbing were detectable, mostly inside the colloid, but some at the periphery as well. A study from Pitsiavas et al. [103] on amiodarone-induced ultrastructural changes in rat thyroids reports on inclusion bodies found in the thyrocytes as well as in the colloid. Allen [104] described similar effects on rats after exposure to excess iodine. Although explanations are still scarce, the observed effects could reflect ongoing cytotoxic processes induced by the test substance. In the present study, no inclusion bodies were found in the thyrocytes but only in the colloid. For several mono- and disubstituted thiourea compounds, cytotoxic effects could be observed [105]. Eventually, these cytotoxic effects might be an explanation for the inclusion bodies detected in the colloid. Adams et al. [106] suggested that the inclusion bodies encapsulated the toxic agent to avoid further toxicity to the cell. In this case, it would make sense to dispose such structures outside the cells, for example, in the colloid as observed.

Epithelial cell height represents a classical parameter to detect thyroid activation [91, 107, 108]. Goleman et al. [109] suggested cell height to be the most sensitive parameter for evaluating perchlorate-exposed Xenopus laevis tadpoles. In the present study, an increase in epithelial cell height was conspicuous at concentrations $\geq 10 \mathrm{mg} / \mathrm{L}$; however, it did not reach the same sensitivity as effects observed in the follicles. Increases in cell height usually coincided with cell crowding and stratification best observable in the highest concentration. These effects are clear signs of a massive hypertrophy triggered by a stimulation of TSH. Ultrastructural studies on amiodarone-exposed rats and PTU- and methimazole-exposed white leghorn chicks revealed massive distortions of the cytological architecture, namely, increased dilation of the rough endoplasmic reticulum and Golgi fields and an increase of secondary lysosomes which hints at a massive activation of protein synthesis $([103,110]$ and own unpublished data on zebrafish).

The effects observed in the thyroid are clear signs of an activation triggered via the hypothalamic-pituitarythyroid axis. The critical hormone involved in this process is TSH, which belongs to the glycoprotein family having an $\alpha$-subunit identical to FSH and LH. The $\beta$-subunit is structurally distinct and confers hormone-specific functions [111]. Until now, it has been unclear if the exposure to thyroid-inhibiting substances leads to any morphological changes in the pituitary of zebrafish or only induces elevated metabolic activity of an unchanged number of pituitary 


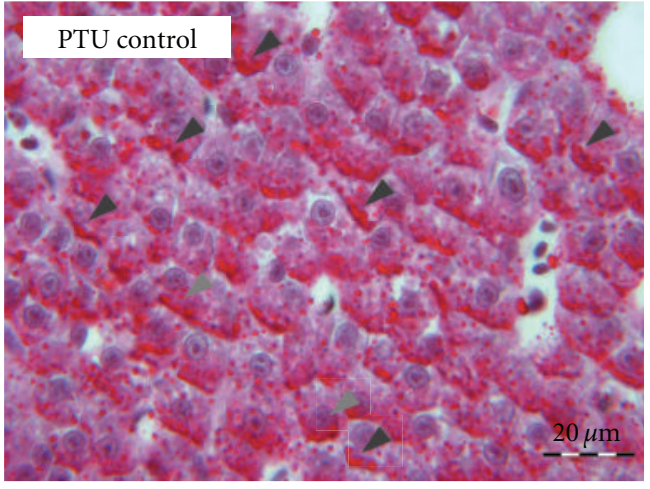

(a)

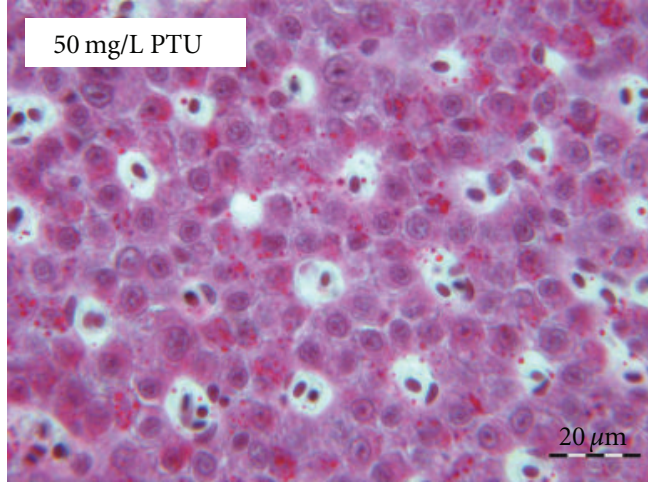

(b)

Figure 12: Representative histopathological alterations in hepatocytes of control (a) and PTU-exposed zebrafish (b). The well-visible glycogen deposits in the control ( (a): $\boldsymbol{\Lambda})$ are depleted in the higher concentration groups. Sections of $2 \mu$ m thickness stained with periodic acid-Schiff (PAS) and Mayer's hematoxylin.

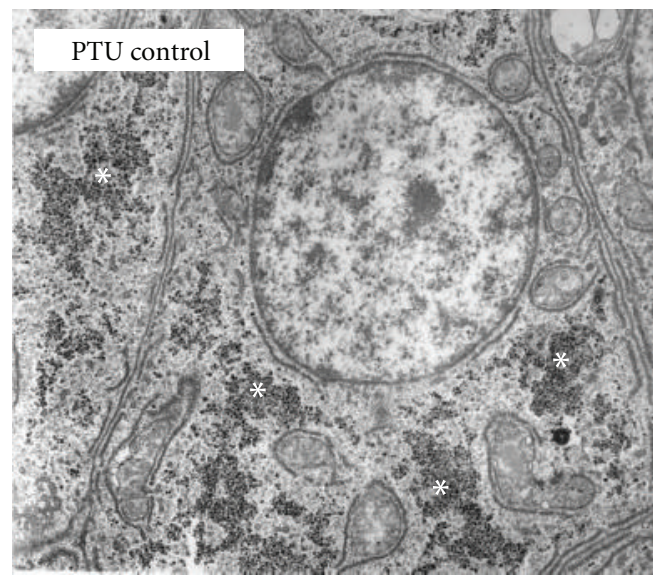

(a)

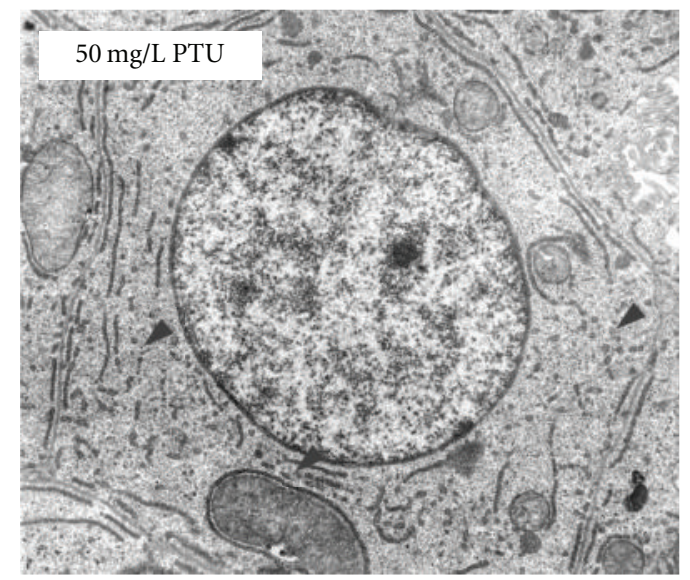

(b)

FIGURE 13: Representative ultrastructural alterations in hepatocytes of control (a) and PTU-exposed zebrafish (b). In the control fish, glycogen storage deposits are clearly visible $((a): *)$, whereas the exposed fish hardly display any glycogen in the cytoplasm. Moderate reductions and fenestrations of the rough endoplasmic reticulum are observable in PTU-exposed zebrafish ((b): $\Delta)$. Furthermore, the number of mitochondria is decreased. Magnification: 10,000x.

cells. Studies in Sprague-Dawley rats report on measurably increased TSH concentrations after exposure to certain EDCs [112], but it was not clear how this was achieved. The present study documents that the decreasing negative feedback induced by exposure to PTU is responsible for proliferations of basophilic cells within the proximal pars distalis. Morphometrical analysis clearly showed that the increase of adenohypophyseal tissue followed a concentration-dependent pattern up to $25 \mathrm{mg} / \mathrm{L}$. Interestingly, the highest exposure group showed a slight decrease, but still statistically significant from the control. Concomitant with adenohypophyseal proliferation, the neurohypophysis slightly decreased, although showing no statistical significance. If these morphological alterations lead to any physiological problems is unknown. We could not detect any signs of abnormal behavior of the fish throughout the experiment. Additional tests are necessary to clarify potential consequences.

To describe the morphological alterations in the pituitary, the ratio of adeno- to neurohypophysis turned out to be a very precise indicator. The effects are in agreement with studies on Wistar rats showing basophilic cell proliferations after exposure to PTU [113]. It is known that TSH-producing cells together with LH- and FSH-producing cells are basophilic and react PAS-positive in histological staining. The control and the highest concentration group revealed a significant increase of TSH-producing cells of the highest exposure group after immunostaining. The increased number of cells is thus capable of producing the TSH concentrations required to stimulate the thyroid. Since only the control and the highest concentration group were immunostained, it is unknown whether this effect is already observable in the lower concentrations, although the measurement of adenohypophyseal surface area implies such an increase. These treatment-related changes of TSH-cell counts contribute to compensate for reduced $\mathrm{TH}$ production due to PTU exposure. Nevertheless, ELISA measurements of T4 contents revealed an obvious decrease of T4 implying the inability of the thyroid system to compensate for the 
inhibition by PTU. The inability to produce sufficient amounts of T4 could be due at least in part to the enormous concentrations of PTU used in the study, which are far from being environmentally relevant.

An important aspect of pituitary regulation is the responsiveness to the negative feedback loop. In our experiments, fish were exposed for 35 days, starting directly after fertilization. At early stages of zebrafish larval development, the absence of thyreotropic hormones does not affect thyroid hormone production or growth of follicles and both processes [60]. On the other hand, nothing is known about the response of the pituitary to environmental exposure at early larval stages. The first thyroid follicles appear around 60 hours postfertilization [60], and an increasing number of follicles appear after the onset of thyroid hormone (T4) production at around $72 \mathrm{hpf}$ [56]. At least in the first few days of development, maternally derived thyroid hormone is likely to compensate for the lack of zygotic thyroid hormone following exposure to endocrine disruptors, although the role of thyroid hormones in early larval development is not clear [114]. The fact that the thyroid gland does not depend on TSH at early larval stages leaves the question when the feedback loop of the inhibited thyroid is established.

Macroscopically observable alterations could be found in whole body length and weight. Considering the importance of thyroid hormones for somatic growth and development, a continuous decline in these two endpoints could be expected. However, a biphasic response pattern was observable in both whole body weight and length with an increase in the lowest concentrations - in case of whole body weight statistically significant-and a decrease in the highest concentration, which was significant in the case of whole body length. One possible explanation for this observation could be reactive overcompensation via TSH. The inhibitory effect of PTU is based on competing with thyroglobulin-linked tyrosine residues and diverting oxidized iodide away from hormone synthesis [72]. The concentration-dependent competitive inhibition probably leads to partially blocked thyroid synthesis still capable of producing certain amounts of T4, which were detected in the ELISA. As PTU does not affect fish deiodinases, the conversion of $\mathrm{T} 4$ to the biologically active hormone T3 should not be affected. In the present experiment, T3 concentrations were not measured, but studies from van der Ven et al. [41] revealed that T3 concentrations remained stable in zebrafish at concentrations of $10 \mathrm{mg} / \mathrm{L}$ PTU. In their study, a significant decrease of T3 could be detected at PTU-concentrations of $100 \mathrm{mg} / \mathrm{L}$, which is far beyond the concentrations tested in this study. The highest measurements of whole body weight and whole body length in the present study were determined at $2.5 \mathrm{mg} / \mathrm{L}$ PTU. Higher exposure groups showed continuous decreases. Since the van der Ven study did not show any decrease of T3 at $1 \mathrm{mg} / \mathrm{L}$ and $10 \mathrm{mg} / \mathrm{L}$, it can be assumed that PTU concentrations of $2.5 \mathrm{mg} / \mathrm{L}$ will not induce T3 decreases either. However, it is likely that PTU-concentrations above $10 \mathrm{mg} / \mathrm{L}$ will cause a decline in T3 levels which may mediate, at least in part, the observed effects on whole body weight and length. These results could explain the biphasic response pattern of whole body length and weight as well as the severe proliferations in the thyroid.

Although the liver is the main site of deiodination [115], histologically detectable effects were scarce. PAS staining revealed clear-cut glycogen depletion at concentrations $\geq 10 \mathrm{mg} / \mathrm{L}$ PTU. Since glycogen is not directly related to the regulation of the hypothalamic-pituitary-thyroid axis, this effect is most probably a general stress symptom caused by the altered thyroid status. Ultrastructurally, decreased numbers of mitochondria and fenestration and reduction of the rough endoplasmic reticulum were common features of concentrations $\geq 10 \mathrm{mg} / \mathrm{L}$. Apparently, fenestration and reduction of the rough endoplasmic reticulum are common reactions of fish hepatocytes to toxic insults, since similar reactions were observed after in vivo exposure to various substances of rainbow trout and zebrafish, respectively [116]. However, specific reactions of the liver with respect to the regulation of thyroidal status could not be observed, rather general toxic effects directly caused by the substance. It is known that PTU has side effects in humans in the treatment of hyperthyroidism $[117,118]$. There are reports of antimitochondrial antibody production in humans [119] which could explain the reduced number of mitochondria. Numerous studies report on necrosis of different severity $[117,120]$; however, no signs of necrosis were visible in the present study, which can possibly be related to the much lower PTU concentrations used in this study together with species-specific differences.

\section{Conclusions}

The present study clearly shows that the zebrafish is sensitive to the effects of PTU and thus may become a useful tool for studying potential thyroid disruptors. The hypothalamicpituitary-thyroid axis showed distinct effects, especially in the thyroid itself and also in the pituitary. Compared to studies in Xenopus laevis, the sensitivity of histologically detectable parameters in the thyroid was as high as or even higher than in Xenopus [19]. The liver revealed rather generalized (unspecific) toxic effects of PTU. Future studies should include downstream markers of thyroid function (e.g., cholesterol levels) to further elucidate these effects. The fact that there are severe morphological changes in the pituitary leaves opens questions whether these changes have negative effects on the regulation of the endocrine system. Further studies are necessary to clarify the responsiveness of the pituitary to inhibiting test substances, since in fish reactions to goitrogens at very early larval stages are unknown and since the establishment of the functioning negative feedback loop remains unclear. Moreover, prolonged test covering the completion of sexual development should be considered to reveal possible effects on sex determinations and gonad development.

\section{Abbreviations}

EDC: Endocrine-disrupting chemical

FSH: Follicle-stimulating hormone

Hpf: Hours postfertilization 
LH: Luteinizing hormone

OECD: Organisation for economic co-operation and Development

PAS: Periodic acid-Schiff (staining)

PTU: Propylthiouracil

T3: Triiodothyronine

T4: Tetraiodothyronine (thyroxin)

TH: $\quad$ Thyroid hormone

TSH: Thyroid-stimulating hormone (thyreotropin).

\section{Acknowledgment}

The first author has been supported by a grant from the Evangelisches Studienwerk e.V. Villigst.

\section{References}

[1] J. Bernanke and H. R. Köhler, "The impact of environmental chemicals on wildlife vertebrates," Reviews of Environmental Contamination and Toxicology, vol. 198, pp. 1-47, 2009.

[2] M. L. Blanton and J. L. Specker, "The hypothalamicpituitary-thyroid (HPT) axis in fish and its role in fish development and reproduction," Critical Reviews in Toxicology, vol. 37, no. 1-2, pp. 97-115, 2007.

[3] T. M. Crisp, E. D. Clegg, R. L. Cooper et al., "Environmental endocrine disruption: an effects assessment and analysis," Environmental Health Perspectives, vol. 106, supplement 1, pp. 11-56, 1998.

[4] A. K. Hotchkiss, C. V. Rider, C. R. Blystone et al., "Fifteen years after "wingspread"-environmental endocrine disrupters and human and wildlife health: where we are today and where we need to go," Toxicological Sciences, vol. 105, no. 2, pp. 235-259, 2008.

[5] W. Kloas, R. Urbatzka, R. Opitz et al., "Endocrine disruption in aquatic vertebrates," Annals of the New York Academy of Sciences, vol. 1163, pp. 187-200, 2009.

[6] P. Matthiessen, "Historical perspective on endocrine disruption in wildlife," Pure and Applied Chemistry, vol. 75, no. 1112, pp. 2197-2206, 2003.

[7] S. Scholz, S. Fischer, U. Gündel, E. Küster, T. Luckenbach, and D. Voelker, "The zebrafish embryo model in environmental risk assessment-applications beyond acute toxicity testing," Environmental Science and Pollution Research, vol. 15, no. 5, pp. 394-404, 2008.

[8] S. Scholz and I. Mayer, "Molecular biomarkers of endocrine disruption in small model fish," Molecular and Cellular Endocrinology, vol. 293, no. 1-2, pp. 57-70, 2008.

[9] J. G. Vos, E. Dybing, H. A. Greim et al., "Health effects of endocrine-disrupting chemicals on wildlife, with special reference to the European situation," Critical Reviews in Toxicology, vol. 30, no. 1, pp. 71-133, 2000.

[10] L. E. Gray Jr., J. Ostby, V. Wilson et al., "Xenoendocrine disrupters-tiered screening and testing: filling key data gaps," Toxicology, vol. 181-182, pp. 371-382, 2002.

[11] S. Jobling, "Review of suggested testing methods for endocrine-disrupting chemicals," Pure and Applied Chemistry, vol. 70, no. 9, pp. 1805-1827, 1998.

[12] C. R. Tyler, S. Jobling, and J. P. Sumpter, "Endocrine disruption in wildlife: a critical review of the evidence," Critical Reviews in Toxicology, vol. 28, no. 4, pp. 319-361, 1998.
[13] N. K. Brar, C. Waggoner, J. A. Reyes, R. Fairey, and K. M. Kelley, "Evidence for thyroid endocrine disruption in wild fish in San Francisco Bay, California, USA. Relationships to contaminant exposures," Aquatic Toxicology, vol. 96, no. 3, pp. 203-215, 2010.

[14] F. Brucker-Davis, "Effects of environmental synthetic chemicals on thyroid function," Thyroid, vol. 8, no. 9, pp. 827-856, 1998.

[15] D. Raldúa and P. J. Babin, "Simple, rapid zebrafish larva bioassay for assessing the potential of chemical pollutants and drugs to disrupt thyroid gland function," Environmental Science and Technology, vol. 43, no. 17, pp. 6844-6850, 2009.

[16] R. M. Rolland, "A review of chemically-induced alterations in thyroid and vitamin A status from field studies of wildlife and fish," Journal of Wildlife Diseases, vol. 36, no. 4, pp. 615-635, 2000.

[17] X. Shi, C. Liu, G. Wu, and B. Zhou, "Waterborne exposure to PFOS causes disruption of the hypothalamus-pituitarythyroid axis in zebrafish larvae," Chemosphere, vol. 77, no. 7, pp. 1010-1018, 2009.

[18] R. T. Zoeller, "Challenges confronting risk analysis of potential thyroid toxicants," Risk Analysis, vol. 23, no. 1, pp. 143162, 2003.

[19] S. J. Degitz, G. W. Holcombe, K. M. Flynn, P. A. Kosian, J. J. Korte, and J. E. Tietge, "Progress towards development of an amphibian-based thyroid screening assay using Xenopus laevis. Organismal and thyroidal responses to the model compounds 6-propylthiouracil, methimazole, and thyroxine," Toxicological Sciences, vol. 87, no. 2, pp. 353-364, 2005.

[20] W. Kloas, "Amphibians as a model for the study of endocrine disruptors," International Review of Cytology, vol. 216, pp. 157, 2002.

[21] R. Opitz, T. Braunbeck, C. Bögi et al., "Description and initial evaluation of a Xenopus metamorphosis assay for detection of thyroid system-disrupting activities of environmental compounds," Environmental Toxicology and Chemistry, vol. 24, no. 3, pp. 653-664, 2005.

[22] R. Opitz, G. Levy, I. Lutz, and W. Kloas, "Development of molecular biomarkers to detect thyroid-disrupting activities of environmental chemicals in Xenopus laevis tadpoles," in Proceedings of the 21st Conference of European Comparative Endocrinologists, R. Keller, H. Dircksen, D. Sedlmeier, and H. Vaudry, Eds., pp. 99-102, Monduzi Editore S.p.A., Bonn, Germany, August 2002.

[23] OECD, OECD Guideline for the Testing of ChemicalsThe Amphibian Metamorphosis Assay. In Effects on Biotic Systems Environmental Health and Safety Publications, Paris, France, 2009.

[24] T. Damstra, S. Barlow, A. Bergman, R. Kavlock, and G. Van der Kraak, "Global assessment of the state-of-the-science of endocrine disruptors, International Programme on Chemical Safety, prepared by an expert group on behalf of the World Health Organisation, the International Labour Organisation, and the United Nations Environment Programme," 2002.

[25] D. M. Janz, "Endocrine System," in The Laboratory Fish, G. K. Ostrander, Ed., chapter 25, Academic Press, San Diego, Calif, USA, 2000.

[26] K. Lagler, J. Bardach, R. Miller, and D. Passino, Ichthyology, John Wiley \& Sons, New York, NY, USA, 2nd edition, 1977.

[27] M. E. Baker, B. Ruggeri, L. J. Sprague et al., "Analysis of endocrine disruption in southern California coastal fish using an aquatic multispecies microarray," Environmental Health Perspectives, vol. 117, no. 2, pp. 223-230, 2009. 
[28] L. R. Iwanowicz, V. S. Blazer, S. D. McCormick, P. A. VanVeld, and C. A. Ottinger, "Aroclor 1248 exposure leads to immunomodulation, decreased disease resistance and endocrine disruption in the brown bullhead, Ameiurus nebulosus," Aquatic Toxicology, vol. 93, no. 1, pp. 70-82, 2009.

[29] R. D. Moccia, J. F. Leatherland, and R. A. Sonstegard, "Increasing frequency of thyroid goiters in Coho salmon (Oncorhynchus kisutch) in the Great Lakes," Science, vol. 198, no. 4315 , pp. $425-426,1977$.

[30] R. D. Moccia, J. F. Leatherland, and R. A. Sonstegard, "Quantitative interlake comparison of thyroid pathology in Great Lakes coho (Oncorhynchus kisutch) and chinook (Oncorhynchus tschawytscha) salmon," Cancer Research, vol. 41, no. 6, pp. 2200-2210, 1981.

[31] I. Morgado, M. A. Campinho, R. Costa, R. Jacinto, and D. M. Power, "Disruption of the thyroid system by diethylstilbestrol and ioxynil in the sea bream (Sparus aurata)," Aquatic Toxicology, vol. 92, no. 4, pp. 271-280, 2009.

[32] J. G. Schnitzler, E. Koutrakis, U. Siebert, J. P. Thomé, and K. Das, "Effects of persistent organic pollutants on the thyroid function of the European sea bass (Dicentrarchus labrax) from the Aegean sea, is it an endocrine disruption?" Marine Pollution Bulletin, vol. 56, no. 10, pp. 1755-1764, 2008.

[33] A. M. Coimbra and M. A. Reis-Henriques, "Tilapia larvae aroclor 1254 exposure: effects on gonads and circulating thyroid hormones during adulthood," Bulletin of Environmental Contamination and Toxicology, vol. 79, no. 5, pp. 488-493, 2007.

[34] H. M. Crane, D. B. Pickford, T. H. Hutchinson, and J. A. Brown, "The effects of methimazole on development of the fathead minnow, Pimephales promelas, from embryo to adult," Toxicological Sciences, vol. 93, no. 2, pp. 278-285, 2006.

[35] O. A. Elsalini and K. B. Rohr, "Phenylthiourea disrupts thyroid function in developing zebrafish," Development Genes and Evolution, vol. 212, no. 12, pp. 593-598, 2003.

[36] F. Liu, A. Gentles, and C. W. Theodorakis, "Arsenate and perchlorate toxicity, growth effects, and thyroid histopathology in hypothyroid zebrafish Danio rerio," Chemosphere, vol. 71, no. 7, pp. 1369-1376, 2008.

[37] S. Mukhi and R. Patiño, "Effects of prolonged exposure to perchlorate on thyroid and reproductive function in zebrafish," Toxicological Sciences, vol. 96, no. 2, pp. 246-254, 2007.

[38] J. W. Park, C. M. Bradford, J. Rinchard et al., "Uptake, elimination, and relative distribution of perchlorate in various tissues of channel catfish," Environmental Science and Technology, vol. 41, no. 21, pp. 7581-7586, 2007.

[39] R. Patiño, M. R. Wainscott, E. I. Cruz-Li et al., "Effects of ammonium perchlorate on the reproductive performance and thyroid follicle histology of zebrafish," Environmental Toxicology and Chemistry, vol. 22, no. 5, pp. 1115-1121, 2003.

[40] M. Picard-Aitken, H. Fournier, R. Pariseau, D. J. Marcogliese, and D. G. Cyr, "Thyroid disruption in walleye (Sander vitreus) exposed to environmental contaminants: cloning and use of iodothyronine deiodinases as molecular biomarkers," Aquatic Toxicology, vol. 83, no. 3, pp. 200-211, 2007.

[41] L. T. van der Ven, E. J. van den Brandhof, J. H. Vos, D. M. Power, and P. W. Wester, "Effects of the antithyroid agent propylthiouracil in a partial life cycle assay with zebrafish," Environmental Science and Technology, vol. 40, no. 1, pp. 7481, 2006.

[42] R. Kirubagaran and K. P. Joy, "Toxic effects of mercurials on thyroid function of the catfish, Clarias batrachus (L.),"
Ecotoxicology and Environmental Safety, vol. 17, no. 3, pp. 265-271, 1989.

[43] R. N. Ram, "Carbofuran-induced histophysiological changes in thyroid of the teleost fish, Channa punctatus (Bloch)," Ecotoxicology and Environmental Safety, vol. 16, no. 2, pp. 106-113, 1988.

[44] R. N. Ram and A. G. Sathyanesan, "Histopathological changes in liver and thyroid of the teleost fish, Channa punctatus (Bloch), in response to ammonium sulfate fertilizer treatment," Ecotoxicology and Environmental Safety, vol. 13, no. 2, pp. 185-190, 1987.

[45] C. A. de Wit, "An overview of brominated flame retardants in the environment," Chemosphere, vol. 46, no. 5, pp. 583-624, 2002.

[46] J. Legler and A. Brouwer, "Are brominated flame retardants endocrine disruptors?" Environment International, vol. 29, no. 6, pp. 879-885, 2003.

[47] P. A. Buffler, M. A. Kelsh, E. C. Lau et al., "Thyroid function and perchlorate in drinking water: an evaluation among California newborns, 1998," Environmental Health Perspectives, vol. 114, no. 5, pp. 798-804, 2006.

[48] Y. Yoshiura, Y. C. Sohn, A. Munakata, M. Kobayashi, and K. Aida, "Molecular cloning of the cDNA encoding the $\beta$ subunit of thyrotropin and regulation of its gene expression by thyroid hormones in the goldfish, Carassius auratus," Fish Physiology and Biochemistry, vol. 21, no. 3, pp. 201-210, 1999.

[49] J. G. Eales, S. B. Brown, D. G. Cyr, B. A. Adams, and K. R. Finnson, "Deiodination as an index of chemical disruption of thyroid hormone homeostasis and thyroidal status in fish," in Environmental Toxicology and Risk Assessment: Standardization of Biomarkers for Endocrine Disruption and Environmental Assessment, D. S. Henshel, M. C. Black, and M. C. Harrass, Eds., vol. 8, American Society for Testing and Materials, 1999.

[50] J. F. Leatherland, R. W. Hilliard, D. J. Macey, and I. C. Potter, "Changes in serum thyroxine and triiodothyronine concentrations during metamorphosis of the Southern Hemisphere Lamprey Geotria australis, and the effect of propylthiouracil, triiodothyronine and environmental temperature on serum thyroid hormone concentrations of ammocoetes," Fish Physiology and Biochemistry, vol. 8, no. 2, pp. 167-177, 1990.

[51] J. G. Eales, "Thyroid function in cyclostomes and fishes," in Hormones and Evolution, E. J. Barrington, Ed., vol. 1, pp. 341436, Academic Press, New York, NY, USA, 1979.

[52] J. C. Raine, A. Takemura, and J. F. Leatherland, "Assessment of thyroid function in adult medaka (Oryzias latipes) and juvenile rainbow trout (Oncorhynchus mykiss) using immunostaining methods," Journal of Experimental Zoology, vol. 290, no. 4, pp. 366-378, 2001.

[53] M. A. N. Wabuke-Bunoti and C. E. Firling, "The prehatching development of the thyroid gland of the fathead minnow, Pimephales promelas (Rafinesque)," General and Comparative Endocrinology, vol. 49, no. 2, pp. 320-331, 1983.

[54] B. Alt, O. A. Elsalini, P. Schrumpf et al., "Arteries define the position of the thyroid gland during its developmental relocalisation," Development, vol. 133, no. 19, pp. 3797-3804, 2006.

[55] T. Wendl, K. Lun, M. Mione et al., "pax2.1 is required for the development of thyroid follicles in zebrafish," Development, vol. 129, no. 15, pp. 3751-3760, 2002.

[56] O. A. Elsalini, J. von Gartzen, M. Cramer, and K. B. Rohr, "Zebrafish hhex, $n k 2.1 a$, and pax2.1 regulate thyroid 
growth and differentiation downstream of Nodal-dependent transcription factors," Developmental Biology, vol. 263, no. 1, pp. 67-80, 2003.

[57] M. De Felice and R. Di Lauro, "Thyroid development and its disorders: genetics and molecular mechanisms," Endocrine Reviews, vol. 25, no. 5, pp. 722-746, 2004.

[58] N. Le Douarin, J. Fontaine, and C. Le Lievre, "New studies on the neural crest origin of the avian ultimobranchial glandular cells-interspecific combinations and cytochemical characterization of $\mathrm{C}$ cells based on the uptake of biogenic amine precursors," Histochemistry, vol. 38, no. 4, pp. 297-305, 1974.

[59] C. S. Le Lievre and N. M. Le Douarin, "Mesenchymal derivatives of the neural crest: analysis of chimaeric quail and chick embryos," Journal of Embryology and Experimental Morphology, vol. 34, no. 1, pp. 125-154, 1975.

[60] B. Alt, S. Reibe, N. M. Feitosa, O. A. Elsalini, T. Wendl, and K. B. Rohr, "Analysis of origin and growth of the thyroid gland in zebrafish," Developmental Dynamics, vol. 235, no. 7, pp. 1872-1883, 2006.

[61] R. S. Kasper, N. Shved, A. Takahashi, M. Reinecke, and E. Eppler, "A systematic immunohistochemical survey of the distribution patterns of $\mathrm{GH}$, prolactin, somatolactin, beta$\mathrm{TSH}$, beta-FSH, beta-LH, ACTH, and alpha-MSH in the adenohypophysis of Oreochromis niloticus, the Nile tilapia," Cell and Tissue Research, vol. 325, no. 2, pp. 303-313, 2006.

[62] R. E. Peter, K. L. Yu, T. A. Marchant, and P. M. Rosenblum, "Direct neural regulation of the teleost adenohypophysis," Journal of Experimental Zoology, vol. 255, no. 4, pp. 84-89, 1990.

[63] D. E. Kime, Endocrine Disruption in Fish, Kluwer Academic Publishers, Boston, Mass, USA, 1998.

[64] F. A. Weltzien, E. Andersson, Ø. Andersen, K. ShalchianTabrizi, and B. Norberg, "The brain-pituitary-gonad axis in male teleosts, with special emphasis on flatfish (Pleuronectiformes)," Comparative Biochemistry and PhysiologyA Molecular and Integrative Physiology, vol. 137, no. 3, pp. 447-477, 2004.

[65] A. García Ayala, M. Villaplana, M. P. García Hernández, E. Chaves Pozo, and B. Agulleiro, "FSH-, LH-, and TSHexpressing cells during development of Sparus aurata L. (Teleostei). An immunocytochemical study," General and Comparative Endocrinology, vol. 134, no. 1, pp. 72-79, 2003.

[66] J. L. Leunissen, A. M. de Leeuw, J. Peute, and H. J. Goos, "Immunocytochemistry of gonadotropic cells and identification of cell types in ultrathin cryosections of the pituitary of the rainbow trout, Salmo gairdneri," Cell and Tissue Research, vol. 226, no. 1, pp. 177-194, 1982.

[67] J. Quesada, M. T. Lozano, A. Ortega, and B. Agulleiro, "Immunocytochemical and ultrastructural characterization of the cell types in the adenohypophysis of Sparus aurata L. (Teleost)," General and Comparative Endocrinology, vol. 72, no. 2, pp. 209-225, 1988.

[68] H. Ueda, G. Young, and Y. Nagahama, "Immunocytochemical identification of thyrotropin (TSH)-producing cells in pituitary glands of several species of teleosts with antiserum to human TSH $\beta$ subunit," Cell and Tissue Research, vol. 231, no. 1, pp. 199-204, 1983.

[69] S. Garcia-Navarro, M. M. Malagon, and F. Gracia-Navarro, "Immunohistochemical localization of thyrotropic cells during amphibian morphogenesis: a stereological study," General and Comparative Endocrinology, vol. 71, no. 1, pp. 116-123, 1988.

[70] L. A. Miranda, D. A. Paz, R. Dezi, and A. Pisanó, "Immunocytochemical and morphometric study on the changes of
TSH, PRL, GH and ACTH cells during the development of Bufo arenarum," Cell and Tissue Research, vol. 283, no. 1, pp. 125-132, 1996.

[71] K. Ogawa, E. Suzuki, and K. Taniguchi, "Immunohistochemical studies on the development of TSH cells in the pituitary of Xenopus laevis larvae," The Journal of Veterinary Medical Science, vol. 57, no. 3, pp. 539-542, 1995.

[72] D. S. Cooper, "Antithyroid drugs," New England Journal of Medicine, vol. 352, no. 9, pp. 905-917, 2005.

[73] A. Orozco, M. C. Jeziorski, P. J. Linser, R. M. Greenberg, and C. Valverde-R, "Cloning of the gene and complete cDNA encoding a type 2 deiodinase from Fundulus heteroclitus," General and Comparative Endocrinology, vol. 128, no. 2, pp. 162-167, 2002.

[74] A. Orozco, P. Villalobos, M. C. Jeziorski, and C. Valverde-R, "The liver of Fundulus heteroclitus expresses deiodinase type 1 mRNA," General and Comparative Endocrinology, vol. 130, no. 1, pp. 84-91, 2003.

[75] JO. P. Sanders, S. Van der Geyten, E. Kaptein et al., "Characterization of a propylthiouracil-insensitive type I iodothyronine deiodinase," Endocrinology, vol. 138, no. 12, pp. 5153-5160, 1997.

[76] J. P. Sanders, S. Van der Geyten, E. Kaptein et al., "Cloning and characterization of type III iodothyronine deiodinase from the fish Oreochromis niloticus," Endocrinology, vol. 140, no. 8, pp. 3666-3673, 1999.

[77] C. Valverde-R, W. Croteau, G. J. Lafleur Jr., A. Orozco, and D. L. ST. Germain, "Cloning and expression of a 5 '-iodothyronine deiodinase from the liver of Fundulus heteroclitus," Endocrinology, vol. 138, no. 2, pp. 642-648, 1997.

[78] D. S. Cooper and S. A. Rivkees, "Putting propylthiouracil in perspective," Journal of Clinical Endocrinology and Metabolism, vol. 94, no. 6, pp. 1881-1882, 2009.

[79] N. Momotani, R. Yamashita, F. Makino et al., "Thyroid function in wholly breast-feeding infants whose mothers take high doses of propylthiouracil," Clinical Endocrinology, vol. 53, no. 2, pp. 177-181, 2000.

[80] K. C. Grim, M. Wolfe, T. Braunbeck et al., "Thyroid histopathology assessments for the amphibian metamorphosis assay to detect thyroid-active substances," Toxicologic Pathology, vol. 37, no. 4, pp. 415-424, 2009.

[81] R. Opitz, S. Hartmann, T. Blank, T. Braunbeck, I. Lutz, and W. Kloas, "Evaluation of histological and molecular endpoints for enhanced detection of thyroid system disruption in Xenopus laevis tadpoles," Toxicological Sciences, vol. 90, no. 2, pp. 337-348, 2006.

[82] R. Opitz, F. Schmidt, T. Braunbeck, S. Wuertz, and W. Kloas, "Perchlorate and ethylenethiourea induce different histological and molecular alterations in a non-mammalian vertebrate model of thyroid goitrogenesis," Molecular and Cellular Endocrinology, vol. 298, no. 1-2, pp. 101-114, 2009.

[83] B. Romeis, Mikroskopische Technik, Urban und Schwarzenberg, 1989.

[84] G. Grandi and M. Chicca, "Early development of the pituitary gland in Acipenser naccarii (Chondrostei, Acipenseriformes): an immunocytochemical study," Anatomy and Embryology, vol. 208, no. 4, pp. 311-321, 2004.

[85] M. J. Karnovsky, "Use of ferrocyanide-reduced osmium tetroxide in electron microscopy," The Journal of Cell Biology, vol. 51, p. 146A, 1971.

[86] A. R. Spurr, "A low-viscosity epoxy resin embedding medium for electron microscopy," Journal of Ultrasructure Research, vol. 26, no. 1-2, pp. 31-43, 1969. 
[87] K. C. Richardson, L. Jarett, and E. H. Finke, "Embedding in epoxy resins for ultrathin sectioning in electron microscopy," Stain technology, vol. 35, pp. 313-323, 1960.

[88] E. S. Reynolds, "The use of lead citrate at high $\mathrm{pH}$ as an electron-opaque stain in electron microscopy," The Journal of Cell Biology, vol. 17, pp. 208-212, 1963.

[89] J. M. Connors, L. J. Huffman, and G. A. Hedge, "Effects of thyrotropin on the vascular conductance of the thyroid gland," Endocrinology, vol. 122, no. 3, pp. 921-929, 1988.

[90] J. M. Connors, L. J. Huffman, M. Michalkiewicz, B. S. Chang, R. D. Dey, and G. A. Hedge, "Thyroid vascular conductance: differential effects of elevated plasma thyrotropin (TSH) induced by treatment with thioamides or TSH-releasing hormone," Endocrinology, vol. 129, no. 1, pp. 117-125, 1991.

[91] W. L. Goleman, L. J. Urquidi, T. A. Anderson, E. E. Smith, R. J. Kendall, and J. A. Carr, "Environmentally relevant concentrations of ammonium perchlorate inhibit development and metamorphosis in Xenopus laevis," Environmental Toxicology and Chemistry, vol. 21, no. 2, pp. 424-430, 2002.

[92] K. Yamasaki, Y. Tago, K. Nagai, M. Sawaki, S. Noda, and M. Takatsuki, "Comparison of toxicity studies based on the draft protocol for the 'Enhanced OECD Test Guideline no. 407' and the research protocol of 'Pubertal Development and Thyroid Function in Immature Male Rats' with 6-n-propyl2-thiouracil," Archives of Toxicology, vol. 76, no. 9, pp. 495501, 2002.

[93] B. Pradet-Balade, C. Burel, S. Dufour et al., "Thyroid hormones down-regulate thyrotropin $\beta$ mRNA level in vivo in the turbot (Psetta maxima)," Fish Physiology and Biochemistry, vol. 20, no. 3, pp. 193-199, 1999.

[94] N. R. Farid and M. W. Szkudlinski, "Minireview: structural and functional evolution of the thyrotropin receptor," Endocrinology, vol. 145, no. 9, pp. 4048-4057, 2004.

[95] D. S. MacKenzie, R. A. Jones, and T. C. Miller, "Thyrotropin in teleost fish," General and Comparative Endocrinology, vol. 161, no. 1, pp. 83-89, 2009.

[96] B. B. Rees, F. A. Sudradjat, and J. W. Love, "Acclimation to hypoxia increases survival time of zebrafish, Danio rerio, during lethal hypoxia," Journal of Experimental Zoology, vol. 289, no. 4, pp. 266-272, 2001.

[97] R. Strecker, T. B. Seiler, H. Hollert, and T. Braunbeck, "Oxygen requirements of zebrafish (Danio rerio) embryos in embryo toxicity tests with environmental samples. Comparative biochemistry and physiology," Toxicology \& Pharmacology, vol. 153, no. 3, pp. 318-327, 2011.

[98] J. D. Via, G. Vandenthillart, O. Cattani, and A. de Zwaan, "Influence of long-term hypoxia exposure on the energy metabolism of Solea solea. 2. Intermediary metabolism in blood, liver and muscle," Marine Ecology Progress Series, vol. 111, no. 1-2, pp. 17-27, 1994.

[99] J. C. Rankin and F. B. Jensen, Fish Ecophysiologyl, Chapman \& Halll, Boca Raton, Fla, USA, 1993.

[100] H. M. Crane, D. B. Pickford, T. H. Hutchinson, and J. A. Brown, "Effects of ammonium perchlorate on thyroid function in developing fathead minnows, Pimephales promelas," Environmental Health Perspectives, vol. 113, no. 4, pp. 396401, 2005.

[101] A. Anderberg, S. Enestrom, and J. Gillquist, "Protein composition in single follicles, homogenates and fine-needle aspiration biopsies from normal and diseased human thyroid," Acta Endocrinologica, vol. 96, no. 3, pp. 328-334, 1981.

[102] B. Anderberg, S. Enestrom, J. Gillquist, and S. Smeds, "Protein composition of the thyroid colloid in patients with hyperthyroidism," Journal of Endocrinology, vol. 86, no. 3, pp. 443-449, 1980.

[103] V. Pitsiavas, P. Smerdely, MU. Li, and S. C. Boyages, "Amiodarone induces a different pattern of ultrastructural change in the thyroid to iodine excess alone in both the BB/W rat and the Wistar rat," European Journal of Endocrinology, vol. 137, no. 1, pp. 89-98, 1997.

[104] E. M. Allen, "The effect of iodine on lipid peroxidation and ultrastructure in the thyroids of BB/Wor rats," Journal of Endocrinological Investigation, vol. 15, no. 7, pp. 519-523, 1992.

[105] R. C. A. Onderwater, J. N. M. Commandeur, E. J. Groot, A. Sitters, W. M. P. B. Menge, and N. P. E. Vermeulen, "Cytotoxicity of a series of mono- and di-substituted thiourea in freshly isolated rat hepatocytes: a preliminary structuretoxicity relationship study," Toxicology, vol. 125, no. 2-3, pp. 117-129, 1998.

[106] P. C. Adams, G. J. Gibson, and A. R. Morley, "Amiodarone pulmonary toxicity: clinical and subclinical features," Quarterly Journal of Medicine, vol. 59, no. 229, pp. 449-471, 1986.

[107] J. G. Eales and S. B. Brown, "Measurement and regulation of thyroidal status in teleost fish," Reviews in Fish Biology and Fisheries, vol. 3, no. 4, pp. 299-347, 1993.

[108] L. A. Miranda, A. Pisanó, and V. Casco, "Ultrastructural study on thyroid glands of Bufo arenarum larvae kept in potassium perchlorate solution," Biocell, vol. 20, no. 2, pp. 147-153, 1996.

[109] W. L. Goleman, J. A. Carr, and T. A. Anderson, "Environmentally relevant concentrations of ammonium perchlorate inhibit thyroid function and alter sex ratios in developing Xenopus laevis," Environmental Toxicology and Chemistry, vol. 21, no. 3, pp. 590-597, 2002.

[110] R. J. Handa and R. B. Chiasson, "Comparative effects of three goitrogenic treatments on White Leghorn chickens," Avian Diseases, vol. 24, no. 4, pp. 916-929, 1980.

[111] J. G. Pierce and T. F. Parsons, "Glycoprotein hormones: structure and function," Annual Review of Biochemistry, vol. 50, pp. 465-495, 1981.

[112] J. C. O'Connor, S. R. Frame, L. G. Davis, and J. C. Cook, "Detection of thyroid toxicants in a Tier I screening battery and alterations in thyroid endpoints over 28 days of exposure," Toxicological Sciences, vol. 51, no. 1, pp. 54-70, 1999.

[113] W. Mellert, K. Deckardt, J. Walter, S. Gfatter, and B. Van Ravenzwaay, "Detection of endocrine-modulating effects of the antithyroid acting drug 6-propyl-2-thiouracil in rats, based on the "Enhanced OECD Test Guideline 407"', Regulatory Toxicology and Pharmacology, vol. 38, no. 3, pp. 368-377, 2003.

[114] D. M. Power, L. Llewellyn, M. Faustino et al., "Thyroid hormones in growth and development of fish," Comparative Biochemistry and Physiology-C Toxicology and Pharmacology, vol. 130, no. 4, pp. 447-459, 2001.

[115] P. P. Morin, T. J. Hara, and J. G. Eales, "Thyroid hormone deiodination in brain, liver, gill, heart and muscle of atlantic salmon (Salmo salar) during photoperiodically-induced parr-smolt transformation. I. Outer- and inner-ring thyroxine deiodination," General and Comparative Endocrinology, vol. 90, no. 2, pp. 142-156, 1993.

[116] T. Braunbeck, V. Storch, and H. Bresch, "Species-specific reaction of liver ultrastructure in Zebrafish (Brachydanio rerio) and trout (Salmo gairdneri) after prolonged exposure to 4-chloroaniline," Archives of Environmental Contamination and Toxicology, vol. 19, no. 3, pp. 405-418, 1990. 
[117] M. Benyounes, C. Sempoux, C. Daumerie, J. Rahier, and A. P. Geubel, "Propylthiouracyl-induced severe liver toxicity: an indication for alanine aminotransferase monitoring?" World Journal of Gastroenterology, vol. 12, no. 38, pp. 6232-6234, 2006.

[118] D. S. Cooper, "The side effects of antithyroid drugs," Endocrinologist, vol. 9, no. 6, pp. 457-467, 1999.

[119] W. A. Parker, "Propylthiouracil-induced hepatotoxicity," Clinical Pharmacology, vol. 1, no. 5, pp. 471-474, 1982.

[120] R. Deidiker and D. E. Demello, "Propylthiouracil-induced fulminant hepatitis: case report and review of the literature," Pediatric Pathology and Laboratory Medicine, vol. 16, no. 5, pp. 845-852, 1996. 


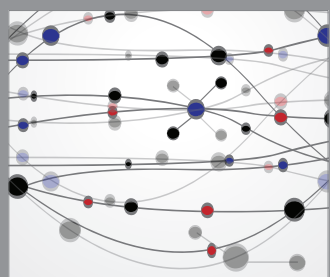

The Scientific World Journal
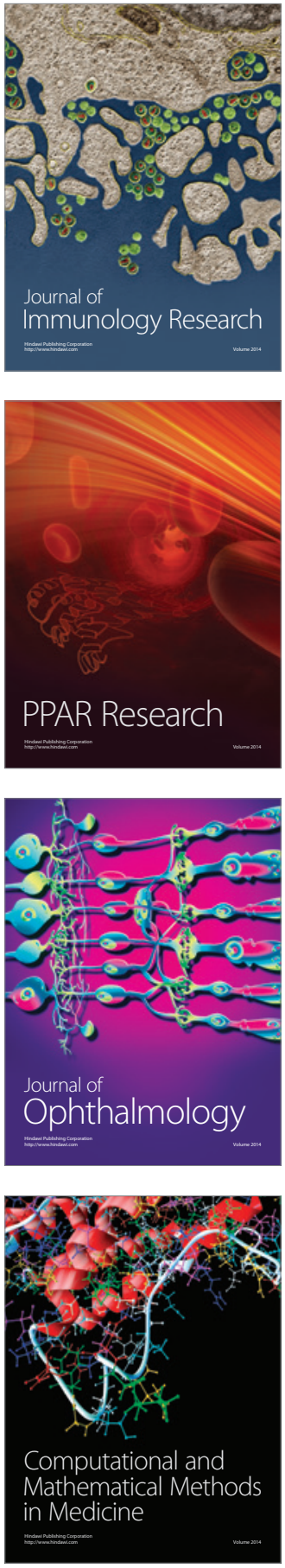

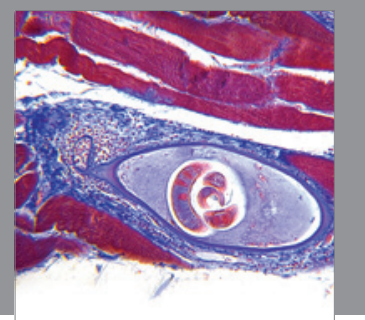

Gastroenterology

Research and Practice
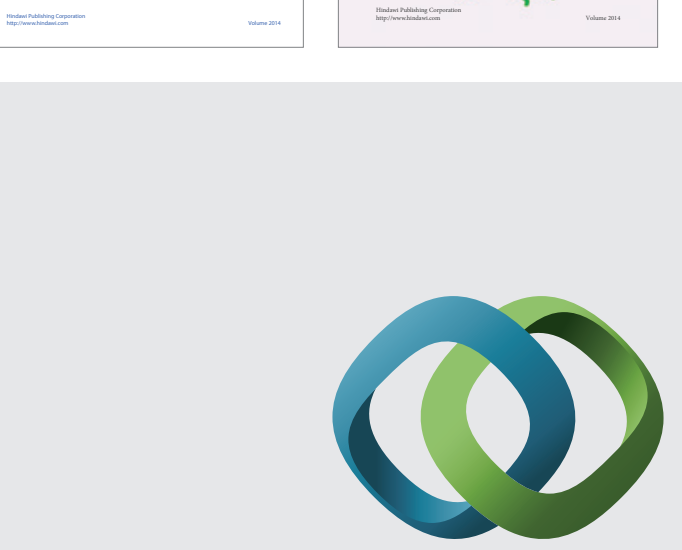

\section{Hindawi}

Submit your manuscripts at

http://www.hindawi.com
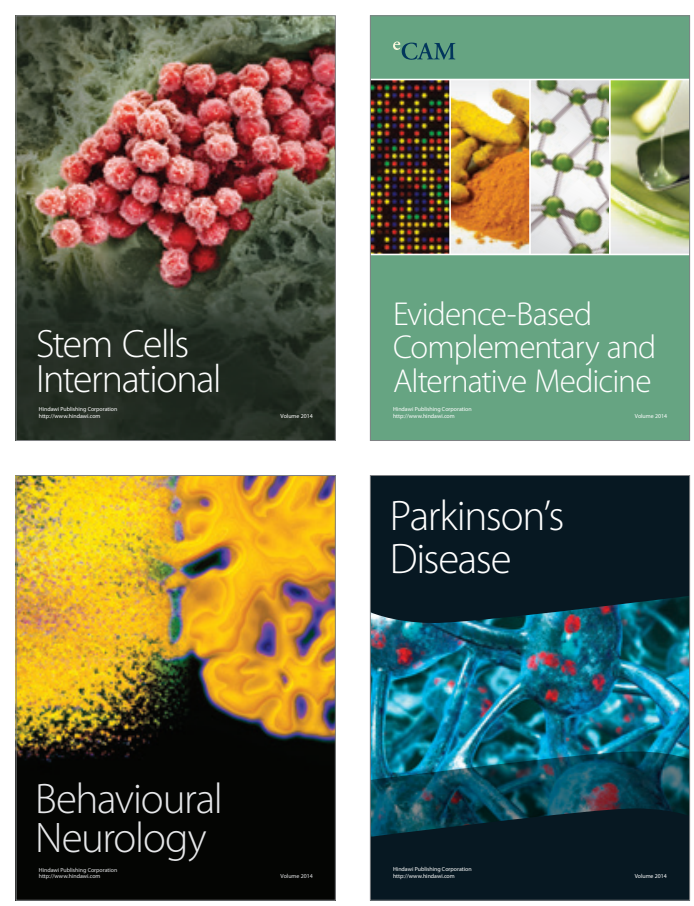

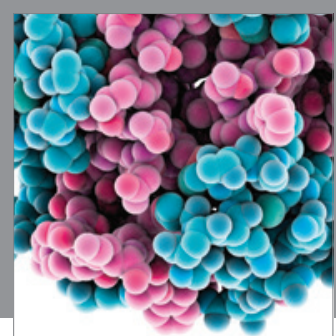

Journal of
Diabetes Research

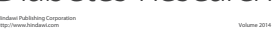

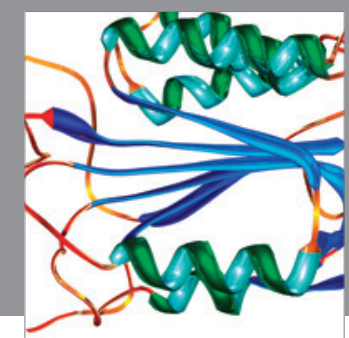

Disease Markers
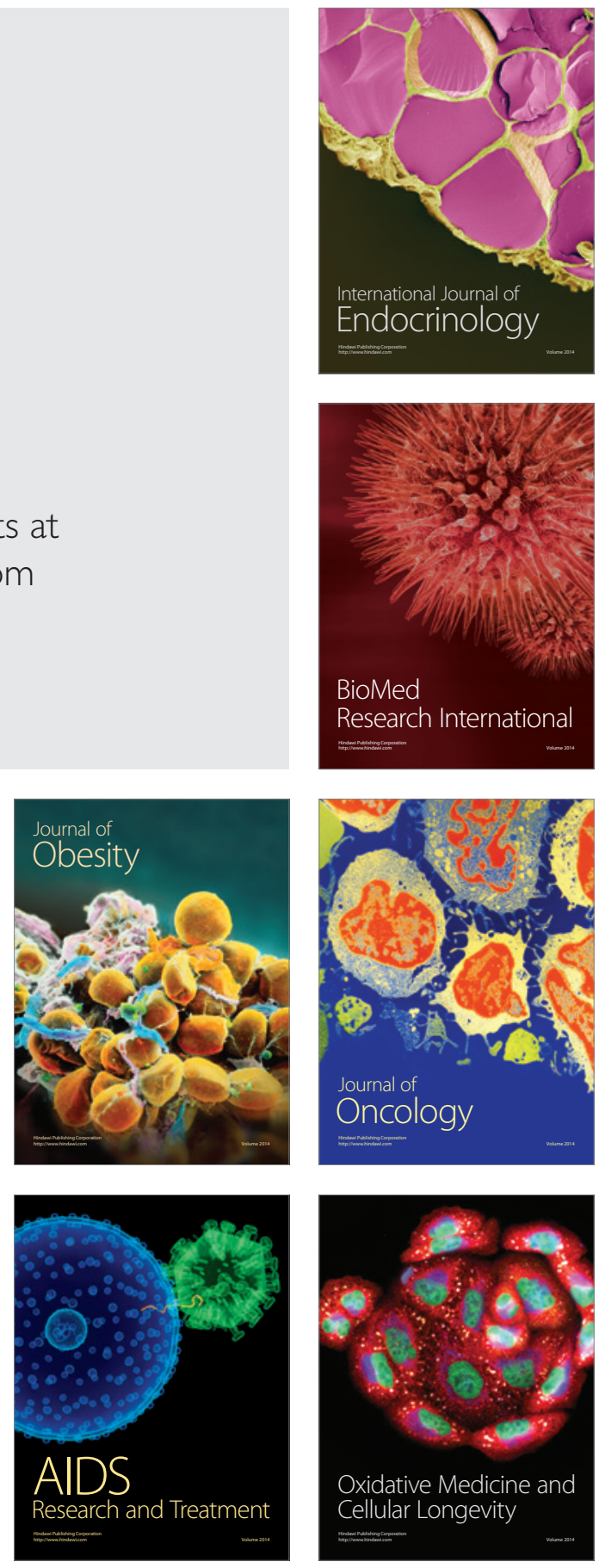